\title{
Improving Performance of Laser and Shaped Tube Electrochemical Machining by Using Retracted Hybrid Tubular Tool Electrode
}

\section{yong yang ( 1261842788@qq.com )}

Ningbo Institute of Materials Technology and Engineering Chinese Academy of Sciences: Ningbo Institute of Industrial Technology Chinese Academy of Sciences

\section{yufeng wang}

Ningbo Institute of Materials Technology and Engineering Chinese Academy of Sciences: Ningbo Institute of Industrial Technology Chinese Academy of Sciences

\section{Yujie Gui}

Ningbo Institute of Materials Technology and Engineering Chinese Academy of Sciences: Ningbo Institute of Industrial Technology Chinese Academy of Sciences

\section{Fuhui Shao}

Ningbo Institute of Materials Technology and Engineering Chinese Academy of Sciences: Ningbo Institute of Industrial Technology Chinese Academy of Sciences

Yulei Li

Ningbo Institute of Materials Technology and Engineering Chinese Academy of Sciences: Ningbo Institute of Industrial Technology Chinese Academy of Sciences

\section{Wenwu Zhang}

Ningbo Institute of Materials Technology and Engineering Chinese Academy of Sciences: Ningbo Institute of Industrial Technology Chinese Academy of Sciences

\section{Research Article}

Keywords: Hybrid machining, Laser and electrochemical machining, retracted tool, materials removal rate, machining precision

Posted Date: May 25th, 2021

DOl: https://doi.org/10.21203/rs.3.rs-542198/v1

License: (c) (i) This work is licensed under a Creative Commons Attribution 4.0 International License. Read Full License 
Version of Record: A version of this preprint was published at The International Journal of Advanced Manufacturing Technology on September 22nd, 2021. See the published version at https://doi.org/10.1007/s00170-021-08097-w. 


\title{
Improving performance of laser and shaped tube electrochemical machining by using retracted hybrid tubular tool electrode
}

\author{
Yong Yanga,b, Yufeng Wanga,b,c, *, Yujie Gui ${ }^{\mathrm{a}, \mathrm{b}}$, Fuhui Shao ${ }^{\mathrm{a}, \mathrm{b}}$, Yulei Li ${ }^{\mathrm{a}, \mathrm{b}}$, Wenwu \\ Zhang ${ }^{\mathrm{a}, \mathrm{b}, \mathrm{c}}$ \\ corresponding author: Yufeng Wang, Ningbo Institute of Materials Technology and Engineering, Chinese \\ E-mail addresses: wangyufeng@nimte.ac.cn (Yufeng Wang), 1261842788@qq.com (Yong Yang) \\ ${ }^{a}$ Ningbo Institute of Materials Technology and Engineering, Chinese Academy of Sciences, Ningbo, 315201, China \\ ${ }^{b}$ Zhejiang Province Key Laboratory of aero engine extreme manufacturing technology, Ningbo, 315201, China \\ ${ }^{c}$ University of Chinese Academy of Sciences, Beijing ,100049, China
}

\begin{abstract}
The coaxial laser has been introduced to shaped tube electrochemical machining (STEM), referred to as LaserSTEM, to enhance the materials removal rate and precision. To address the issue of central residual formation during the Laser-STEM process, which limited the machining stability and feeding rate, the retracted hybrid tubular electrode was applied. The formation mechanisms and effects of the W-shaped central residual were analyzed. Simulation and experiments were conducted to study the impact of the retracted length of the tubular electrode. Simulation results showed that a retracted length of 1-1.5 mm of the inner low-refractive layer could improve the electric current density distribution homogeneity to remove the W-shaped central residual in the machining area. The electric current density distribution homogeneity in the machining zone has been decreased by $38 \%$ by utilizing the hybrid tubular electrode with a retracted length of $2.0 \mathrm{~mm}$. With a proper retracted length, the laser coupling efficiency exceeded $74.5 \%$. Hence, the retracted hybrid tubular electrode could act as both the tool electrode and optical waveguide in the Laser-STEM process. Experimental results proved that the machining efficiency and precision of Laser-STEM could be enhanced by utilizing the retracted hybrid tubular electrode. With the retracted length deg rising from $0 \mathrm{~mm}$ to $1.5 \mathrm{~mm}$, the maximum feeding speed increased by $373 \%$, and the machining precision was improved by $42.2 \%$. The maximum feeding rate of $4.1 \mathrm{~mm} / \mathrm{min}$ has been achieved using the retracted hybrid tubular electrode in the Laser-STEM process, which has been improved by 105\%, compared with the available maximum feeding rate of the tubular electrode in the STEM process. Finally, the small holes with a diameter of $1.4 \mathrm{~mm}$ and an aspect ratio of 15 have been processed by Laser-STEM with the retracted hybrid tubular electrode.
\end{abstract}

Keywords: Hybrid machining, Laser and electrochemical machining, retracted tool, materials removal rate, machining precision

\section{Introduction}

Electrochemical machining (ECM) removes workpiece materials based on the controllable anodic dissolution process. A voltage is applied between the counter polarities, and the electrolyte flows through the interelectrode gap [1]. ECM has the advantages of no heat-affected zone (HAZ), no tool wear, and high surface finish while processing difficult-to-cut materials such as titanium alloys and superalloys [2,3]. Nowadays, ECM has found wide applications in diverse industrial fields, such as aerospace, automobile, electronics, and medical devices [4],[5],[6]. However, the machining precision of ECM was always deteriorated by stray current induced corrosion, and the machining efficiency was lower than that of other machining processes such as laser beam processing (LBM) and 
electric discharge machining (EDM). Improving the machining precision and efficiency of ECM has become an urgent issue in both industrial and academic areas.

As a variant of ECM, the shaped tube electrochemical machining (STEM) could achieve interventional drilling of conductive workpiece materials [7]. STEM utilizes the hollow metal tubular electrodes with a side insulating coating as the cathode. The electrolyte flows through the hollow tubular electrode to the machining area and flows out from the side machining gap with high pressure and high flow rate, enhancing the diffusion rate of heat and reaction products from the machining zone. With the feeding of the tubular electrode towards the workpiece, small holes with a high aspect ratio as large as 300:1 could be obtained by STEM [8]. Thus, STEM has been widely applied to process small holes with high aspect ratio and surface integrity. Typically, STEM has been employed to process the film cooling holes in the turbine blade in aero engineering [9].

Numerous studies have been conducted to improve the material removal rate and machining accuracy of STEM. McGeough et al. have revealed that the electric current is the most crucial influence factor of material removal rate (MRR), using the established theoretical model [10]. Rajurkar introduced the pulse current to STEM and suggested that the joule heat and reaction products could be removed during pulse interval time, promoting machining stability and accuracy [11],[12]. Skoczypiec et al. studied the cavitation phenomenon and pressure distribution along with the gap thickness, and proposed that ultrasonic vibration of electrode tool could enhance the transportation rate of electrolytic products and increase machining accuracy [13]. Wang et al. studied the STEM process with the constant electrolyte flow to promote the ability to remove insoluble reaction products from the machining area. Results demonstrated that the constant pressurized electrolyte flow could improve the surface finish of the machined holes and increase the machining efficiency [14]. Deepak et al. derived the governing equations of ECM, and stressed that the MRR increased with the increase of voltage and the decrease of the initial interelectrode gap (IEG) [15].

However, the uneven distribution of the electric current density in the machining zone produces a central residual column or spike in the central machining zone during the STEM process, where the electric current density is the smallest [16]. Suppose the tool electrode feeding rate is too high., in that case, the residual column could enter into the inner hole of the tubular electrode, which would limit the electrode feeding rate and the machining stability due to the electrolyte blocking. An electric short circuit would also destroy the tool electrode. Conventionally, to eliminate the central residual in the STEM process, the higher voltage, lower tool electrode feeding rate, and higher concentrated electrolyte were employed [17]. However, the machining precision could be compromised. Hewidy et al. applied an orbital motion to the tool electrode to diminish the residual, but the requirement of the equipment precision was high, and the processing accuracy was also decreased [18]. Zhang et al. proved that the shape of the hole bottom depends on the equilibrium gap, and the relationship between the bottom shape and the machining parameters such as applied voltage and electrode feed rate was studied by experiments. However, the conflict between the efficiency and the precision of the process remains unresolved [19]. The contradiction between the formation of central residual and the high feeding rate of the tool electrode has to be resolved to improve both the machining efficiency and precision of STEM.

Recently, laser has been introduced to the ECM process to improve both the machining precision and efficiency [20]. It has been demonstrated that the application of laser in ECM could improve the materials removal rate (MRR) by $54 \%$ and reduce the taper angle by $65 \%$ [21]. Our research team has introduced coaxial laser to the STEM firstly and proposed hybrid laser and STEM (Laser-STEM) method [16]. Results showed that the machining precision and material removal rate were improved by $60.7 \%$ and $122.7 \%$, respectively, compared with the STEM process [22]. Laser-STEM coaxially coupled the laser beam within the inner hole of a tubular electrode by internal total reflection with the electrolyte jet [23]. The tubular electrode served both as the cathode for electrochemical reaction and the optical guide for laser propagation [24]. An insulating low-refractive-index layer was adhered to the inner hole of the tubular electrode during the Laser-STEM process to meet the requirement of 
internal total reflection of the laser beam within the electrolyte jet. However, the electric current density was also prevented from distributing to the center of the machining area under a low voltage level, which isolated the interaction between two energies to a certain extent, resulting in the formation of residual between the laser machining area and electrochemical dissolution area, as illustrated in Fig. 1a. The voltage of higher than $16 \mathrm{~V}$ was used in the Laser-STEM process to eliminate the residual, in which the distribution range of the electric current density was expanded. However, a larger voltage would also deteriorate the machining precision. Thus, both the precision and machining efficiency of the Laser-STEM were limited.

In this paper, the retracted hybrid tubular electrode has been introduced to improve both the machining precision and efficiency of the Laser-STEM process. A tubular electrode with the retracted inner layer, rather than the flat-end tool used in the previous studies, has been utilized for expanding the electric current density towards the machining area center. The distribution of the electric current density in the machining area was simulated. The residual could be removed by the improved electric current density at the center of machining area. Experiments were conducted to verify the effects of tool end geometry on the machining efficiency and precision of the hybrid Laser-STEM process.

\section{Principles of laser-STEM with the retracted hybrid tool}

\subsection{Mechanisms of Laser-STEM with retracted tubular electrode}

Fig. $1 \mathrm{~b}$ illustrates mechanisms of the Laser-STEM using a retracted hybrid tubular electrode. A Teflon layer with low refractivity $\left(n_{1}=1.24\right)$ was inserted into the inner hole of the metal capillary tube with the controlled retracted length. Because the optical refractivity of the Teflon layer is smaller than that of the electrolyte $\left(n_{2}=1.35\right)$, the laser beam could transmit restricted within the Teflon layer by internal total reflection, with the incident angle larger than the critical angle $\left(\sin ^{-1}\left(n_{1} / n_{2}\right)\right)$. Thus, the hybrid tubular electrode could act as both the cathode and optical guide. In the previous study, the distribution of the laser intensity in the machining area is similar to the Gaussian distribution, thus the materials at the center of machining area could be removed by laser processing, with a taper angle [22]. Also, the electrochemical machining mainly occurred under the metal tube. Thus, a residual could be formed between the laser processing and electrochemical dissolution area, as shown in Fig. 1a. The volume of the residual would be increased with a low voltage, with the highly localized electrochemical dissolution under the tubular electrode. With the existence of the residual, the electrolyte flow field may be disturbed, and thus the laser could not transmit to the machining area with high efficiency. Also, the residual could block the electrolyte, and the machining products could not be flowed out, which would deteriorate the machining stability or stop the machining process with the short circuits. The short circuits induced plasma could destroy the hybrid tubular electrode and the workpiece, and cease the machining process.
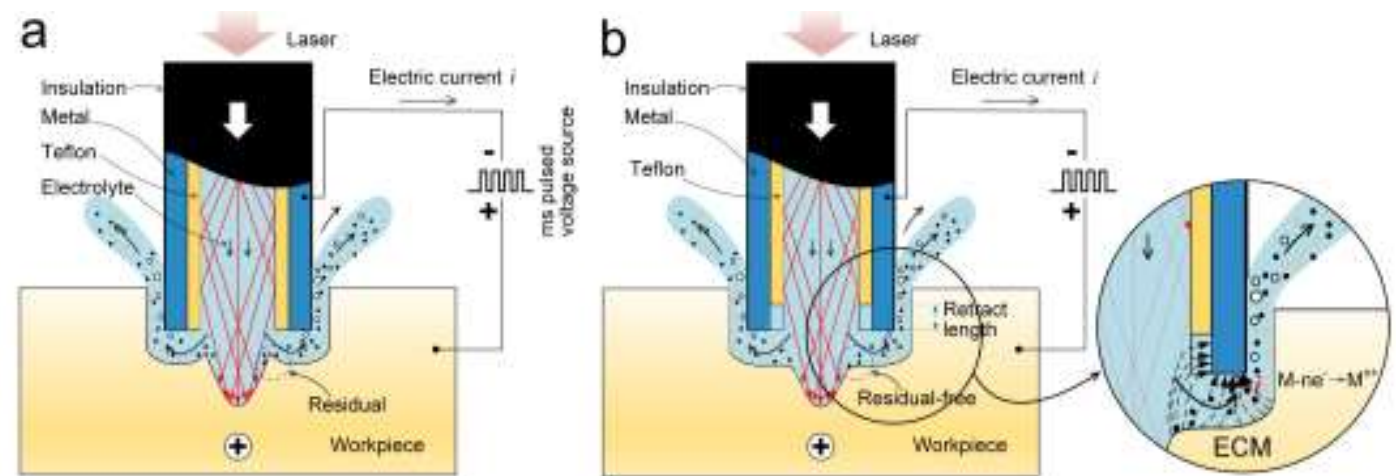

Fig. 1. Schematic diagram of the hybrid laser and shaped tube electrochemical machining (Laser-STEM) process using (a) a flatended hybrid tubular electrode, and (b) a retracted hybrid tubular electrode.

Compared with the Laser-STEM process using a flat-ended hybrid tubular electrode, the electric current 
density at the machining area center is higher while using the retracted hybrid tubular electrode. Thus, the residual, formed between the laser processing and electrochemical dissolution area, could be removed by the increased electric current density. In contrast, the current density distribution in the center of machining zone decrease. When the electrode inner layer was retracted, the current density near the center of the machining zone increased, the residual could be removed by electrochemical dissolution, as illustrated in Fig. 1b. Thus, the materials at the machining area could be removed much homogeneously, which is preferred to enhancing the machining stability and improving the feeding rate of the tubular electrode.

\subsection{Simulation of electric current density in the machining area}

The effects of the retracted tubular electrode on the distribution of electric current density distribution have been researched by simulation. Fig. 2 shows the electrical model of the Laser-STEM process utilizing a retracted tubular electrode, where $D_{\mathrm{g}}$ was the inner diameter of the reflective layer and was set to $0.5 \mathrm{~mm} ; D_{\text {ein }}$ and $D_{\text {eout }}$ was the inner and out diameter of the metal capillary tube and were set to $0.85 \mathrm{~mm}$ and $1.15 \mathrm{~mm}$, respectively. $U_{\mathrm{w}}$ was the voltage applied between the hybrid tubular electrode and the workpiece and was set to $10 \mathrm{~V}$. The initial interelectrode gap (IEG) was set to $0.2 \mathrm{~mm}$, and the retracted length deg varied ranging from $0 \mathrm{~mm}$ to $2 \mathrm{~mm}$.

With the particular conditions and assumptions [25], the potential $\varphi$ in the IEG could be calculated by the Laplace' equation:

$$
\nabla^{2} \varphi=0
$$

The boundary condition of the model was defined as:

$$
\begin{aligned}
& \varphi \mid \Gamma_{2}=U_{w} \\
& \varphi \mid \Gamma_{6,7,13,14}=0 \\
& \frac{\partial \varphi}{\partial n} \mid \Gamma_{1,3-5,8-12,15,16}=0 \\
& \stackrel{\text { ü }}{n} \cdot \stackrel{\text { u }}{j} \mid \Gamma_{2-4,10-12}=0 \quad \text { (At the insulating layer) }
\end{aligned}
$$

The electric current density $\mathrm{j}$ is then defined by Ohm's law as the normal derivative of the potential, i.e.,

$$
j=-\kappa \cdot \nabla \varphi
$$

Based on Faraday's law, the electrochemical machining rate is proportional to the electric current density [10]. Thus, the distribution of the electric current density could reflect the machining profile of EMM. The distribution of electric current density at the machining area was analyzed using COMSOL Multiphysics. This simulation has ignored the effects of laser irradiation, on the assumption that the laser parameters were kept constant in different conditions. The parameters used in the simulation were listed in Table 1 . The density of the current line distributions in the machining zone are shown in Fig. 3, While deg $=0 \mathrm{~mm}$ and $2 \mathrm{~mm}$. The electric current start from the high potential (workpiece) surface and end at the low potential (electrode) surface, simulation result manifested that the electric current density mainly distributed under the hollow metal tube cross-section when deg $=0 \mathrm{~mm}$, while approaching the center of processing area the current line density decreased rapidly. When the retracted length deg rose to $2 \mathrm{~mm}$, the simulation result demonstrated that the electric current line density distribution within the machining area increased, compared with that no retraction, that is, $\operatorname{deg}=0$. 


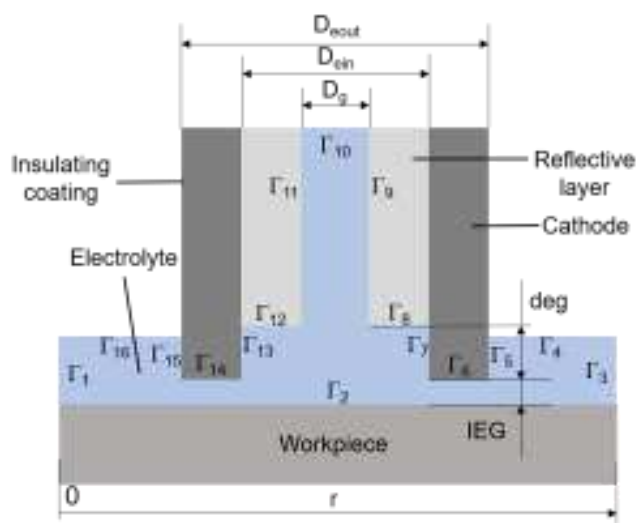

Fig. 2. The electric potential domain of the hybrid laser and shaped tube electrochemical machining process.
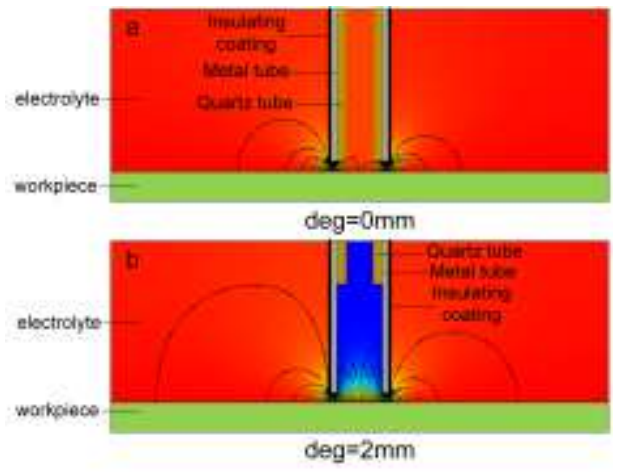

Fig. 3. The electric current line distributions in machining zone with $10 \mathrm{~V}$ voltage and $0.2 \mathrm{~mm}$ IEG, with the retracted length of (a) $\operatorname{deg}=0 \mathrm{~mm}$, (b) deg= $2 \mathrm{~mm}$.

Fig. 4a shows the distribution of electric current density under different retracted length of deg. The electric current increases sharply and appears as a peak under the metal capillary tube. The smallest electric current density occurs at the machining area center. It has been revealed that the minimum electric current density increased with the increase of retracted length deg. The minimum value of the electric current density increased from $6.8 \mathrm{~A} / \mathrm{cm} 2$ to $34.75 \mathrm{~A} / \mathrm{cm} 2$, increasing by $411 \%$, while the retracted length deg rose from 0 to $2.0 \mathrm{~mm}$. On the contrary, the maximum electric current density varied little by rising from $60.5 \mathrm{~A} / \mathrm{cm} 2$ to $68.0 \mathrm{~A} / \mathrm{cm} 2$, while the retracted length deg rose from 0 to $2.0 \mathrm{~mm}$. Therefore, with the increase of retracted length, the machining rate of electrochemical dissolution increase, thus the residual could be removed by the enhanced electrochemical machining.

a

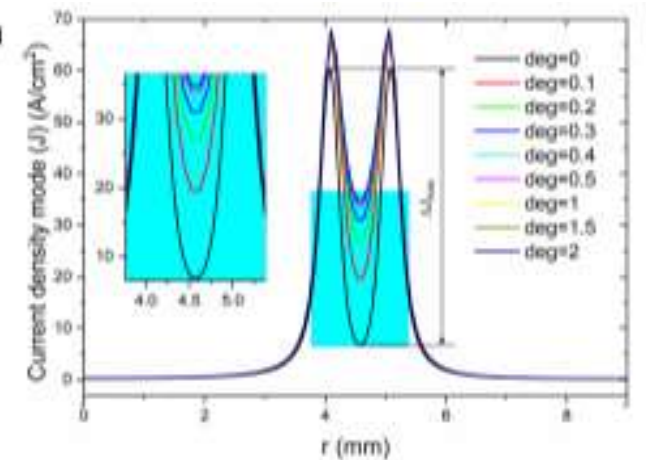

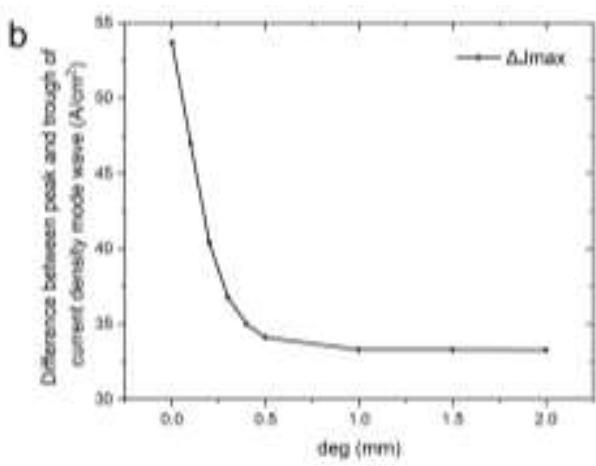

Fig. 4. (a) The distribution of electric current density at the machining area in the Laser-STEM process, (b) Variation of the difference between the maximum and minimum electric current density $\Delta J_{\max }$ with the retracted length.

$\Delta J_{\max }$ is defined as the difference between the maximum and minimum electric current density with the particular retracted length. It represented the machining capability of ECM at the center of the machining area, to some extent. As shown in Fig. $4 \mathrm{~b}$, the value of $\Delta J_{\max }$ has decreased with the increase of the retracted length. It decreased from $53.7 \mathrm{~A} / \mathrm{cm}^{2}$ to $33.3 \mathrm{~A} / \mathrm{cm}^{2}$, a decrease of $38 \%$, while the retracted length deg rose from 0 to $2.0 \mathrm{~mm}$. When the retracted length was larger than $1.0 \mathrm{~mm}$, the value of $\Delta J_{\max }$ kept at around $33.3 \mathrm{~A} / \mathrm{cm}^{2}$. Thus, the retracted length of larger than $1.0 \mathrm{~mm}$ could enhance the machining rate of ECM at the center of the machining 
area to remove the central residual peak.

\section{Experimental}

\subsection{Experimental setup}

Fig. 5 shows the diagram of the developed hybrid laser-STEM experimental setup. The laser beam transmits through a set of reflective mirrors and focuses on the tubular electrode inlet by the focusing lens. The coupling status between the laser beam and tubular electrode inlet could be monitored by the CCD system. The laserelectrode coupling unit was fixed on the z-axis, which has a travel range of $300 \mathrm{~mm}$, and a resolution of $0.001 \mathrm{~mm}$. As the photograph of the experimental setup developed for Laser-STEM is shown in Fig. 6, the z-axis was fixed on the gantry structure made of marble. The laser was applied to the machining area through the inner hole of the tubular electrode by internal total reflection. The electrolyte supply system provides the electrolyte with the controlled pressure and flow rate. A pulsed voltage source with a frequency of $20 \mathrm{kHz}$ was applied between the metal tube and workpiece. The workpiece and metal tube were connected to the positive and negative polarities, respectively. The workpiece has been fixed in an electrolysis tank assembled on the $\mathrm{x}-\mathrm{y}$ axis, which has a travel range of $250 \mathrm{~mm} \times 250 \mathrm{~mm}$, and a resolution of $0.001 \mathrm{~mm}$.

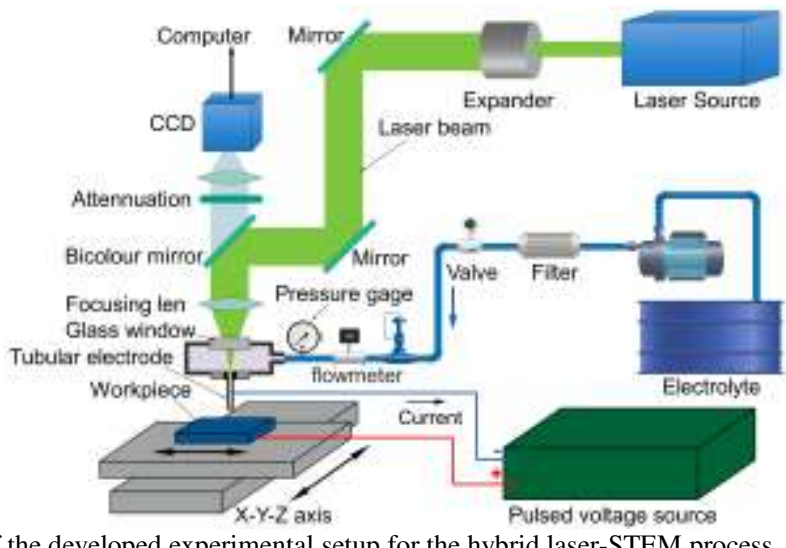

Fig. 5. Schematic diagram of the developed experimental setup for the hybrid laser-STEM process.

In the hybrid Laser-STEM process, an initial interelectrode gap (IEG) was pre-set firstly, utilizing the electric short circuits and the moving of the hybrid tubular electrode in the z-direction. After opening the electrolyte supply system, the pulse voltage source, and the laser sequentially, the tubular electrode feeds towards the workpiece with the controlled feeding rate. When the holes were processed completely, the hybrid tubular electrode retreated and moved to the next machining area by moving the workpiece in the $x-y$ plane.

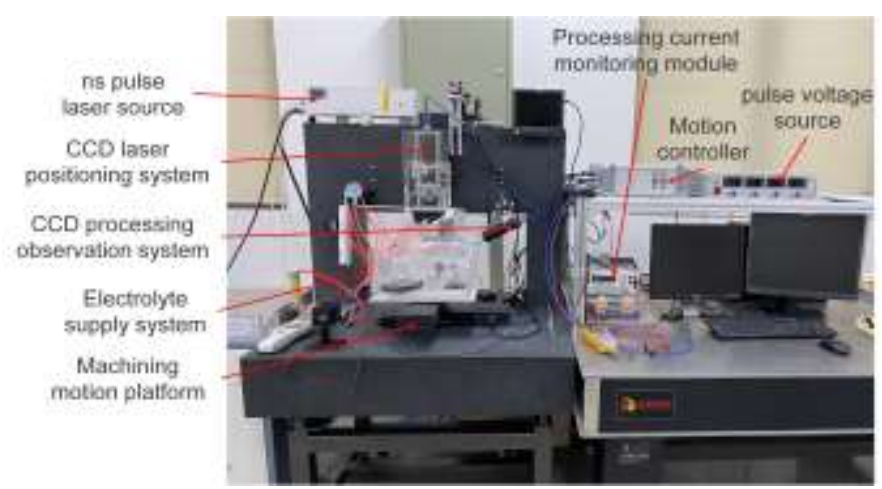

Fig. 6. Photograph of the developed experimental setup for the hybrid laser-STEM process.

\subsection{Preparation of retracted hybrid tubular tool electrode}

An instrument has been developed to prepare the hybrid tubular electrode with the controlled retracted length of the low refractive index layer, as shown in Fig. 7a. The hybrid tubular electrode contains an insulating layer, metal capillary tube, and concentric low-reflective layer, with an outer diameter of $1.15 \mathrm{~mm}$ and an inner diameter 
of $0.5 \mathrm{~mm}$. The concentric low-reflective layer was installed in the inner hole of the metal capillary tube. Both the electrolyte and laser beam could enter into the machining area through the inner hole of the hybrid tubular electrode [22]. The side electrical insulating layer could limit the current distribution within the machining region to improve the machining accuracy and decrease the taper angle. As the above analysis, the electric current density at the central machining zone would increase rapidly with the larger retracted length. The electrode was fixed in the positioning thimble, and the retracted length of the low-refractive layer was controlled by a screw micrometer, with the inner rod moving straight in the axial direction. Fig. $7 \mathrm{~b}$ shows the photograph of the developed instrument for preparing the retracted hybrid tubular electrode with the controlled retracted length deg. Fig. 7c shows the image of the cross-section of the hybrid tubular electrode.
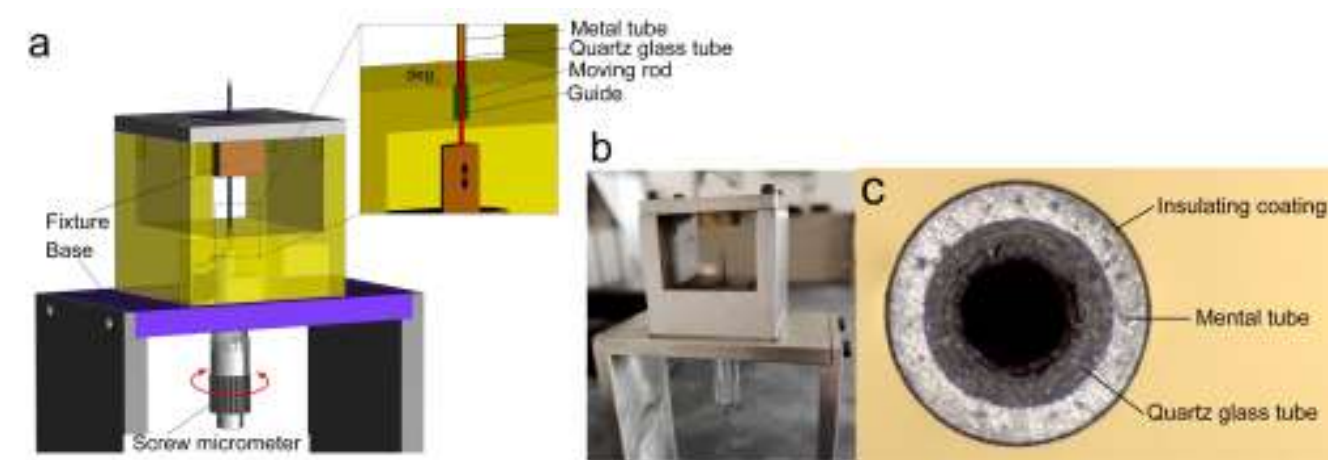

Fig. 7. (a) Three-dimensional model of the developed instrument for preparing the hybrid tubular electrode with the controlled retracted length, (b) the photograph of this developed instrument, (c) the cross-section of the developed hybrid tubular electrode with the controlled retracted length.

\subsection{Materials and Measurement}

The workpieces made of Inconel 718 with a thickness of $2 \mathrm{~mm}$ and the surface roughness of Ra $1.6 \mu \mathrm{m}$ were processed by the Laser-STEM process. The conductive layer of the electrode was made from the titanium capillary tube with an inner diameter of $0.85 \mathrm{~mm}$ and an outer diameter of $1.15 \mathrm{~mm}$, and an insulating layer was coated on the outer sidewall of the conductive tube with a thickness of $30 \mu \mathrm{m}$. A solution of sodium nitrate $\left(\mathrm{NaNO}_{3}\right)$ was used as the electrolyte. The other experimental conditions are listed in Table 1. Microcavities and small holes were processed by the Laser-STEM process. After processing, the workpiece was treated by ultrasonic cleaning in deionized water and ethanol for $30 \mathrm{~min}$, sequentially.

A laser scanning microscope (Keyence, VK-X200K) was used to measure the three-dimensional (3-D) geometrical dimensions of the processed holes and cavities. The optical microscope was employed to observe the morphology of the inlet and outlet. Scanning electron microscopy (SEM, Hitachi, SU5000) was used to measure the microscopic feature of the machining zone and the distribution of elements. Three holes were processed with each set of parameters to measure the average diameter of the machined cavities and small holes. In our experiments, the precision of Laser-STEM has been represented by the machining side gap $\Delta$, which could be expressed as:

$$
\Delta=\left(D_{a v}-d\right) / 2
$$

where $D_{\text {av }}$ is the average diameter, and $d$ is the tubular electrode outer diameter.

Table 1. Experimental parameters for Laser-STEM with retracted tool electrode.

\begin{tabular}{lll}
\hline \hline parameter & unit & value \\
Electrolyte & $\mathrm{g} / \mathrm{L}$ & $125 \mathrm{~g} / \mathrm{L} \mathrm{NaNO}_{3}$ \\
Electrolyte temperature & ${ }^{\circ} \mathrm{C}$ & 24 \\
Electrolyte pressure & $\mathrm{MPa}$ & 0.2 \\
Voltage $\left(U_{\mathrm{w}}\right)$ & $\mathrm{V}$ & $10-16$ \\
Initial IEG & $\mathrm{mm}$ & 0.2 \\
Electrode feeding rate & $\mathrm{mm} / \mathrm{min}$ & 0.6 \\
Duty cycle & $\%$ & 50 \\
Laser power & $\mathrm{W}$ & 10 \\
Temperature & ${ }^{\circ} \mathrm{C}$ & 24 \\
\hline
\end{tabular}




\section{Results and discussion}

\subsection{Influences of retracted length on laser coupling efficiency}

A laser power meter was employed to measure the laser power at the inlet and outlet of the hybrid tubular electrode, respectively. The laser coupling efficiency was defined as the division between the outlet laser power and the inlet laser power. Fig. 8 shows the variation of laser coupling efficiency with electrode inlet laser power, with the hybrid tubular electrode length of $55 \mathrm{~mm}$. Results demonstrated a decreasing trend of the laser coupling efficiency with the increase of retracted length deg, attributed to the lack of reflective layer on the tubular electrode exit. With the increase of inlet laser power, the higher laser intensity at the focus spot may lead to the optical breakdown of electrolyte, producing plasma plume and cavitation bubbles in the laser irradiation region, negatively affect the coupling efficiency of the laser. However, the laser coupling efficiency was larger than $74.5 \%$ and kept at around $80 \%$ when the laser power at the electrode inlet reached $13.44 \mathrm{~W}$, meaning that this system could make full use of the laser energy in the Laser-STEM process. Therefore, the retracted hybrid tubular electrode could act as both the tool electrode and optical waveguide in the Laser-STEM process.

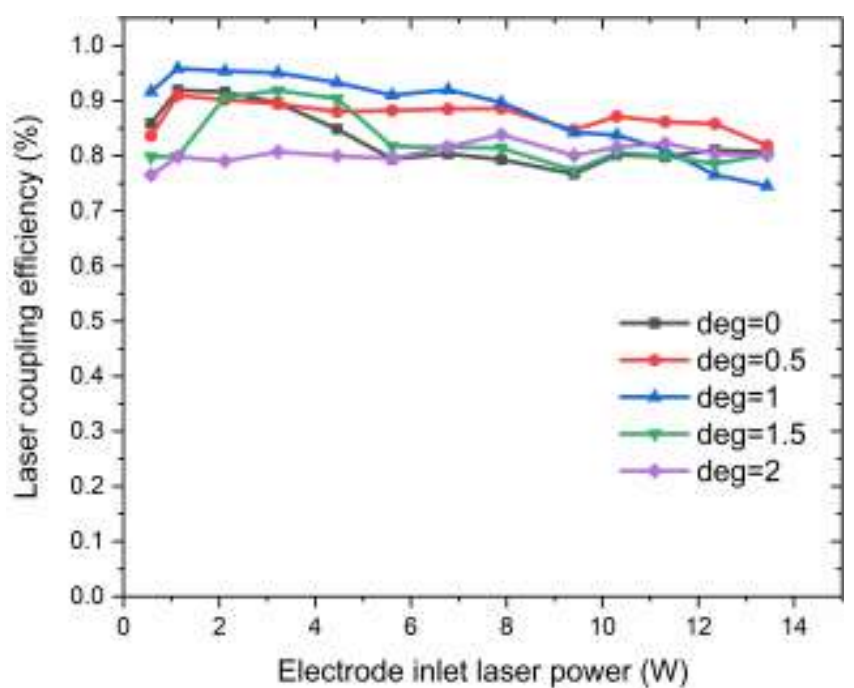

Fig. 8. Variation of the laser coupling efficiency with the electrode inlet laser power and the retracted length of deg ranging from 0 to $2 \mathrm{~mm}$.

\subsection{Comparison of Laser-STEM with retracted and flat-ended electrode}

Fig. 9 compares the 3-D morphology of the machined cavities by STEM and Laser-STEM. Fig. 9a, 9c, and 9e show the cavities processed by the STEM process without laser assistance. Fig. 9b, 9d, and 9f show the cavities processed by laser-STEM with the laser power of $10 \mathrm{~W}$. It could be found that when the laser beam was coupled into the electrode and acted at the machining zone, the residual peak in the center place could be removed, which means that the possibility of short circuit caused by the center residual could be reduced. In contrast, as shown in Fig. 9a, 9c, and 9e, it could be revealed that the height of the residual peak decreased with the deg increased from 0 to $1.5 \mathrm{~mm}$. The profiles of the processed cavities are shown in Fig. 10. It was more evidence that the material in the center zone can hardly be removed with deg $=0 \mathrm{~mm}$ and voltage of $14 \mathrm{~V}$, even when the feed depth of the electrode is greater than $700 \mu \mathrm{m}$. However, the material removal rate in the center machining area increased when the deg value increased to $0.5 \mathrm{~mm}$, while the processing capacity did not increase with the deg grows further, which was consistent with the simulation results. 

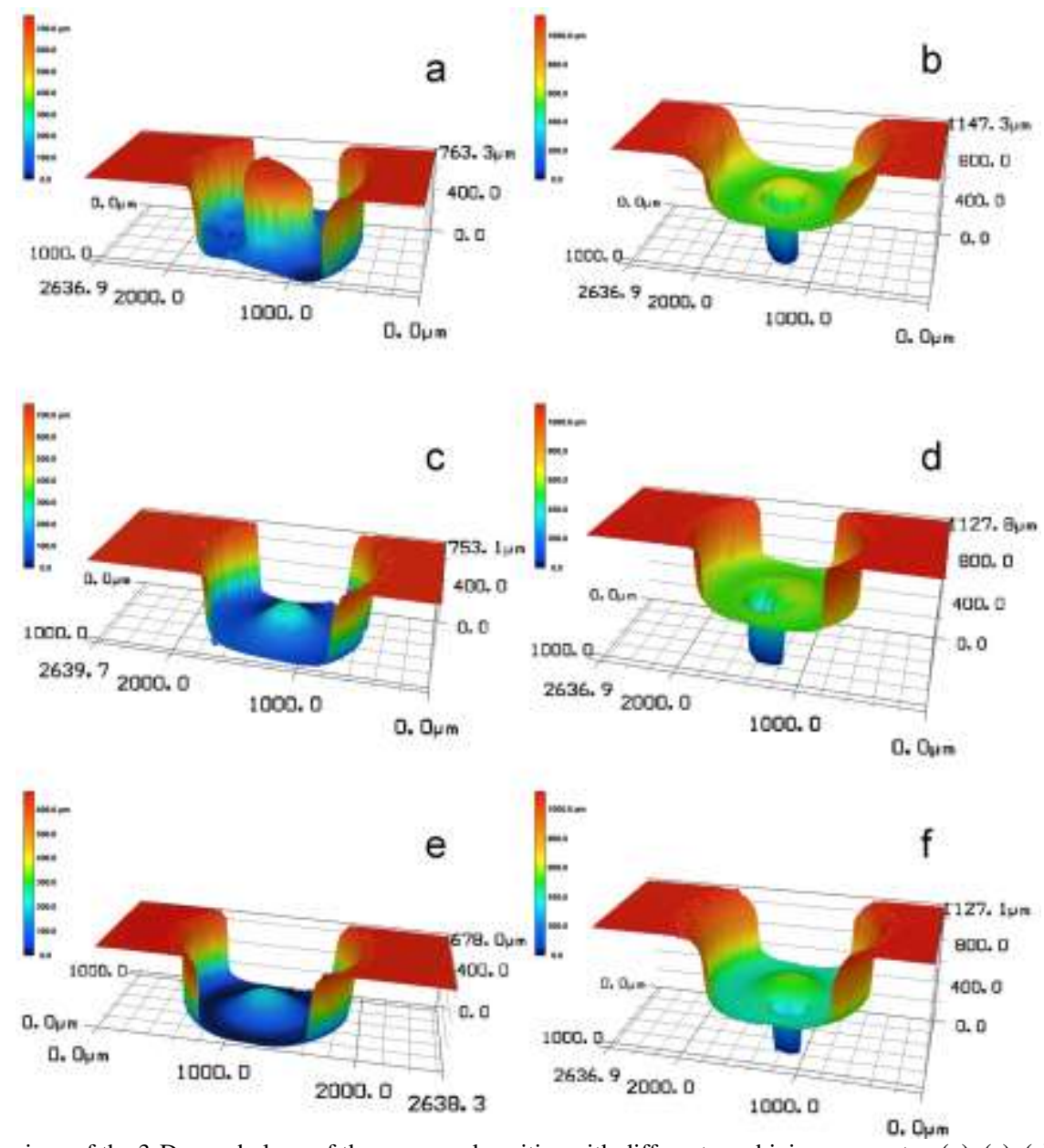

Fig. 9. Comparison of the 3-D morphology of the processed cavities with different machining parameter, (a), (c), (e) the cavities processed by STEM without laser, (b), (d), (f) the cavities processed by the Laser-STEM process, (a), (b) deg $=0 \mathrm{~mm}$ and $\mathrm{U}_{\mathrm{w}}=$ $14 \mathrm{~V},(\mathbf{c}),(\mathbf{d}) \operatorname{deg}=0.5 \mathrm{~mm}$ and $\mathrm{U}_{\mathrm{w}}=14 \mathrm{~V},(\mathbf{e}),(\mathbf{f}) \mathrm{deg}=1.5 \mathrm{~mm}$ and $\mathrm{U}_{\mathrm{w}}=14 \mathrm{~V}$.

Fig. 9b, 9d, and 9f show the morphology of the machined cavities utilizing the Laser-STEM process. Due to the high-efficiency laser processing in the central machining area, the central depth was much larger than that of the peripheral area of the processed cavities. As shown in Fig. 10b, the morphology of the bottom of the machined cavities almost overlapped. It could be demonstrated the height of the residual part between the laser processing area and ECM area decreased with the increase of retracted length, contributed by the increased electric current density in the central machining zone. Moreover, with the increase of the retracted length, the diameter of the processed cavities decreased, and the machining depth increased, which positively affected the side gap and increased the machining depth, thus improving the machining accuracy and efficiency.
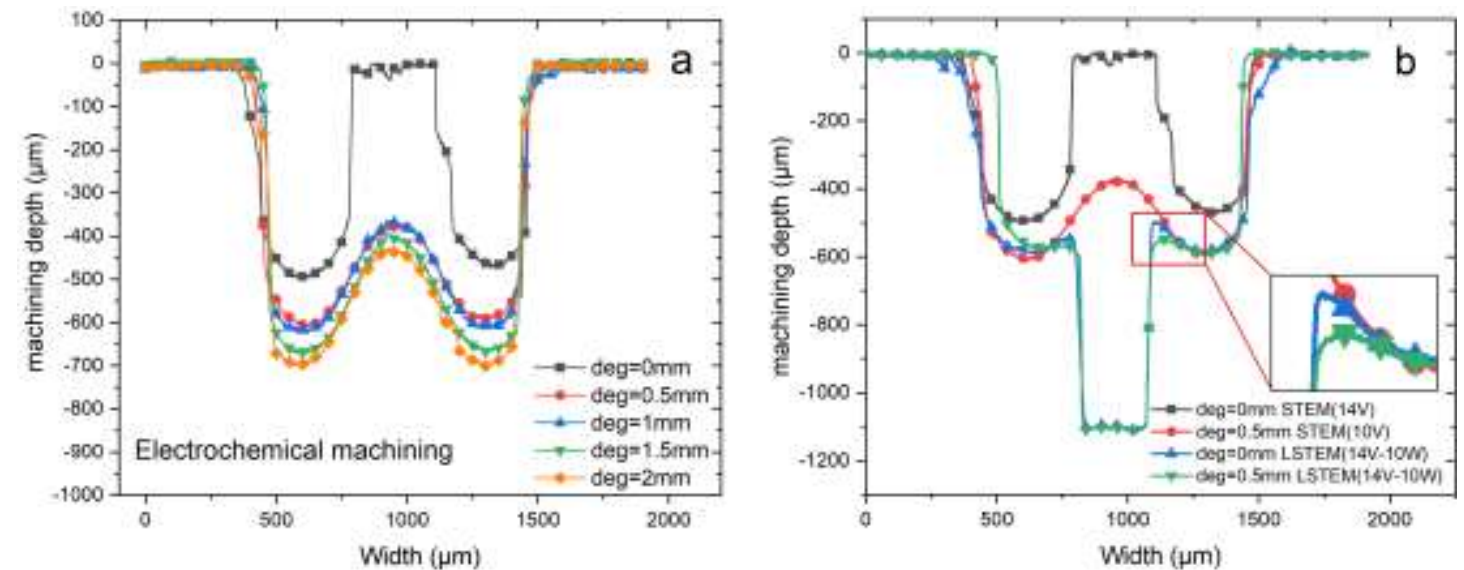

Fig. 10. (a) The cross-sectional profiles of processed cavities by STEM without laser assistance, (b) Comparison of the crosssectional profiles of the processed cavities by STEM without laser assistance and the Laser-STEM process. 
Fig. 11 shows the SEM images of the cross-sectional profile of a processed cavity by the Laser-STEM process. It could be revealed that the central machining depth was much higher due to the higher machining efficiency of laser processing than ECM. Also, the $\mathrm{W}$-shaped residual was formed between the laser processing and ECM area, as discussed in section 2. Fig. 11c shows that the processed surface at the bottom of the cavity where laser-assisted electrochemical dissolution occurs. The laser-induced high temperature could accelerate the machining rate of the ECM process. It could be noted that the morphology at the surrounding machining area was similar to that of machined by ECM. Fig. 11d shows the processed surface where laser processing dominated with a high laser intensity in the central area, which caused material melting and solidification under the electrolyte environment, where the content of oxygen was much higher than that machined by ECM at the peripheral area of the cavity, as the EDS (Energy Dispersive Spectrometer) analysis shown in Fig. 11c. The SEM images also proved that the proposed hybrid Laser-STEM could simultaneously apply the coaxial laser and electrochemical energy to the machining zone along the same axis. Therefore, in the Laser-STEM process, the workpiece materials in the central area were mainly removed by laser processing, whereas the materials in the surrounding area were mainly removed by laser-assisted ECM, which could guarantee that the machined surface has higher surface integrity.

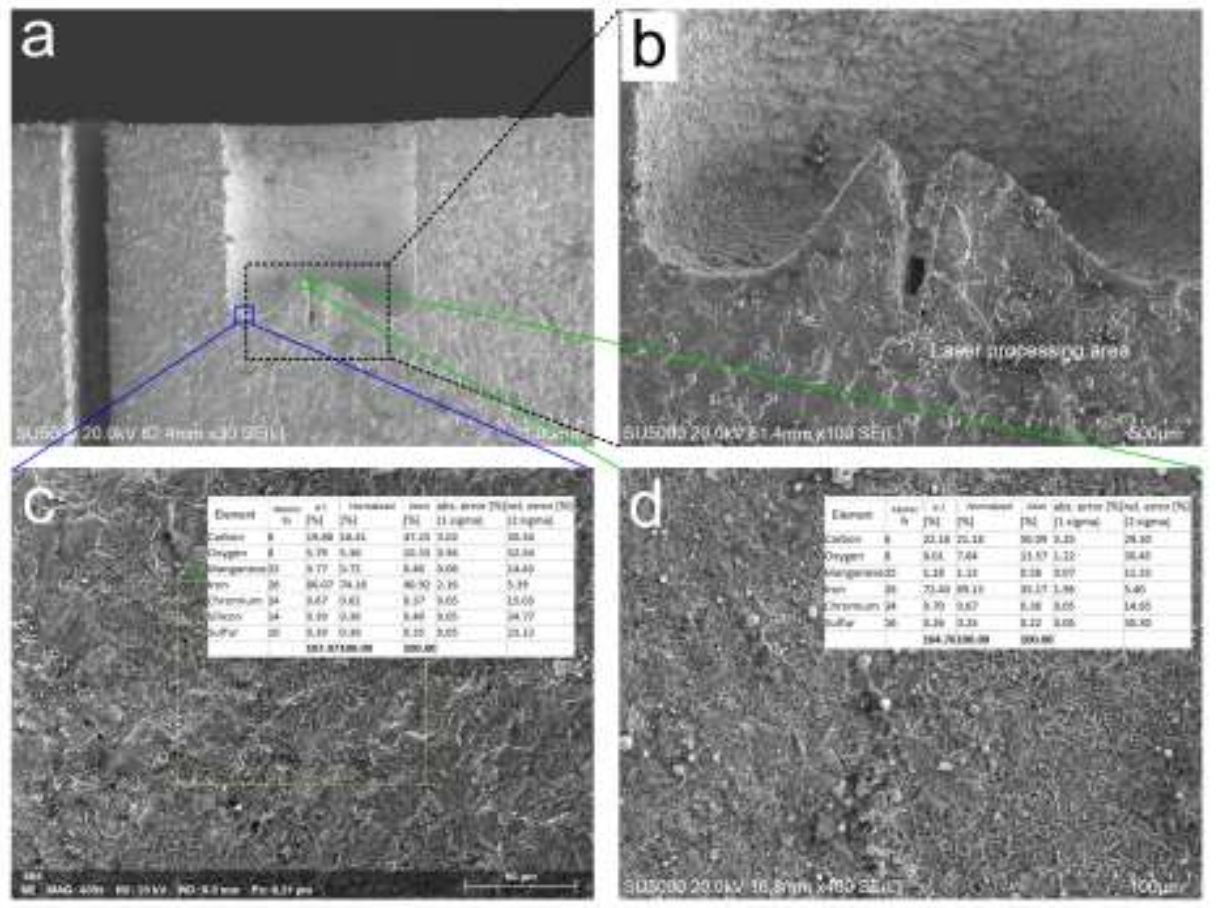

Fig. 11. (a) SEM images of the cavities processed by the Laser-STEM process, (b) the enlarged SEM image of the central machining area, (c) SEM image and EDS analysis of laser assisted ECM area, (d) SEM image and EDS analysis of the laser processing area.

The shape of the processed cavities by the STEM and the Laser-STEM were schematically illustrated in Fig. 12a, which was used to demonstrate the residual peak height at the bottom of the machining area. The positive value means protrusion, and the negative value means cavity. Fig. 12b shows the residual peak height variation with the retracted length deg and voltage in the STEM and the laser-STEM processes. It could be observed that in the STEM process, the residual height showed a decrease from $758 \mu \mathrm{m}$ to $208 \mu \mathrm{m}$, a reduction of $72.6 \%$, with the retracted length increased from $0 \mathrm{~mm}$ to $1.5 \mathrm{~mm}$. When deg=0 mm, the residual height decreased sharply from 758 $\mu \mathrm{m}$ to $318 \mu \mathrm{m}$ with the laser power of $6 \mathrm{~W}$ in the Laser-STEM process, and the residual height decreased from 318 $\mu \mathrm{m}$ to $90 \mu \mathrm{m}$ with the laser power increased from $6 \mathrm{~W}$ to $10 \mathrm{~W}$. The residual showed as the $\mathrm{W}$-shape in the laserSTEM process. When deg=0.5 $\mathrm{mm}$ and $1.5 \mathrm{~mm}$, the residual height decreased to $38 \mu \mathrm{m}$ and $-10 \mu \mathrm{m}$ with a laser power of $10 \mathrm{~W}$, respectively. The residual peak with a negative value means no residual was formed at the machining area when the laser power exceeded a particular value. With a higher laser power, both the laser processed and electrochemical machining areas increase, removing the residual in the machining area. Therefore, a 
larger retracted length and higher laser power were preferred to eliminate the residual volume, and thus improve the machining stability of Laser-STEM.
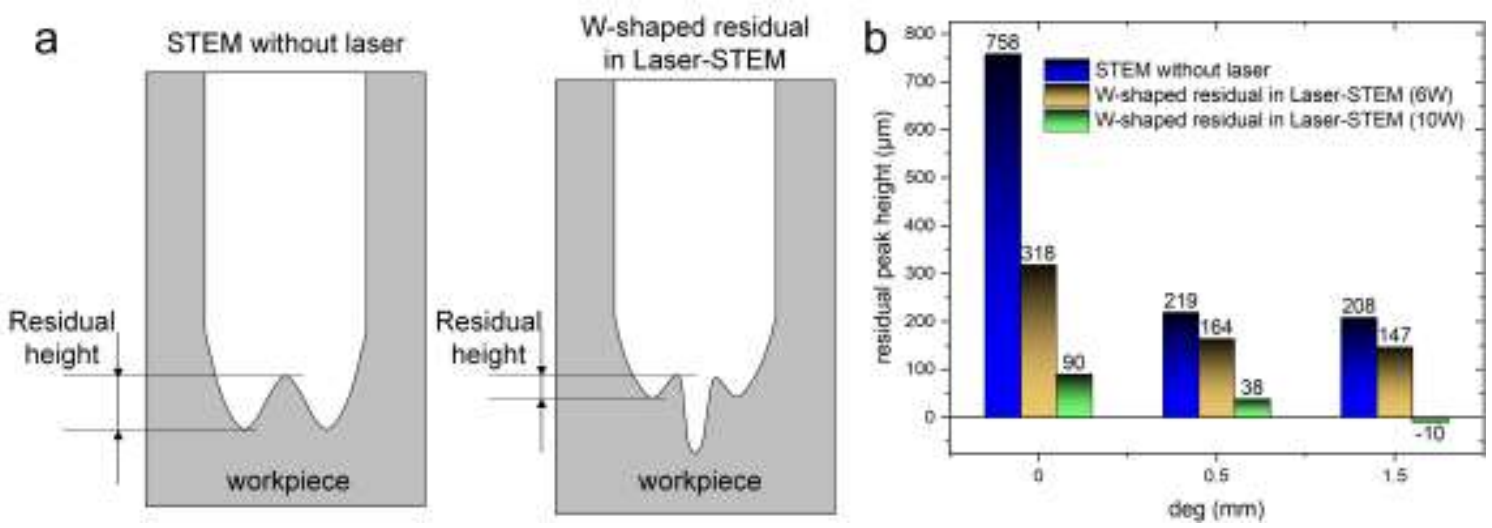

Fig. 12. (a) Schematic illustration of the residual peak height of the machined cavities processed by the STEM and the LaserSTEM processes, (b) variation of the residual peak height with the retracted length of $0,0.5 \mathrm{~mm}$, and $1.5 \mathrm{~mm}$ in the STEM and the Laser-STEM processes.

\subsection{Influences of retracted length on machining precision}

Fig. 13 shows the side gap of the machined holes with the different retracted length deg and processing voltage in the STEM and the laser-STEM processes. As shown in Fig. 13a, the side gap increased with the rising of voltage. It could be observed that the side gap increased sharply while the retracted length deg ranging from 0 to $0.5 \mathrm{~mm}$, and then slowly increased to a stable value while the retracted length deg was ranging from 0.5 to $2.0 \mathrm{~mm}$, in the STEM process. Experimental results revealed no drilling capability with no retract and a voltage of $10 \mathrm{~V}$. When the voltage rose to $12 \mathrm{~V}$, the machining side gap jumps up to around $1290 \mu \mathrm{m}$ and kept roughly constant with increasing voltage. When the retracted length deg increased from 0 to $0.5 \mathrm{~mm}$, the current distribution in the center area increased gradually. Moreover, the electric current for removing materials by electrochemical dissolution increased as the machining area of the cathode increased, which would lead to a larger machining side gap. With the retracted length deg increasing from $0.5 \mathrm{~mm}$ to $2.0 \mathrm{~mm}$, the electric current density in the center of machining zone would keep increasing, as the simulation results, leading to the removal of the materials in the center machining area. Thus, the machining precision of the STEM could not be improved by utilizing the retracted hybrid tubular tool electrode.
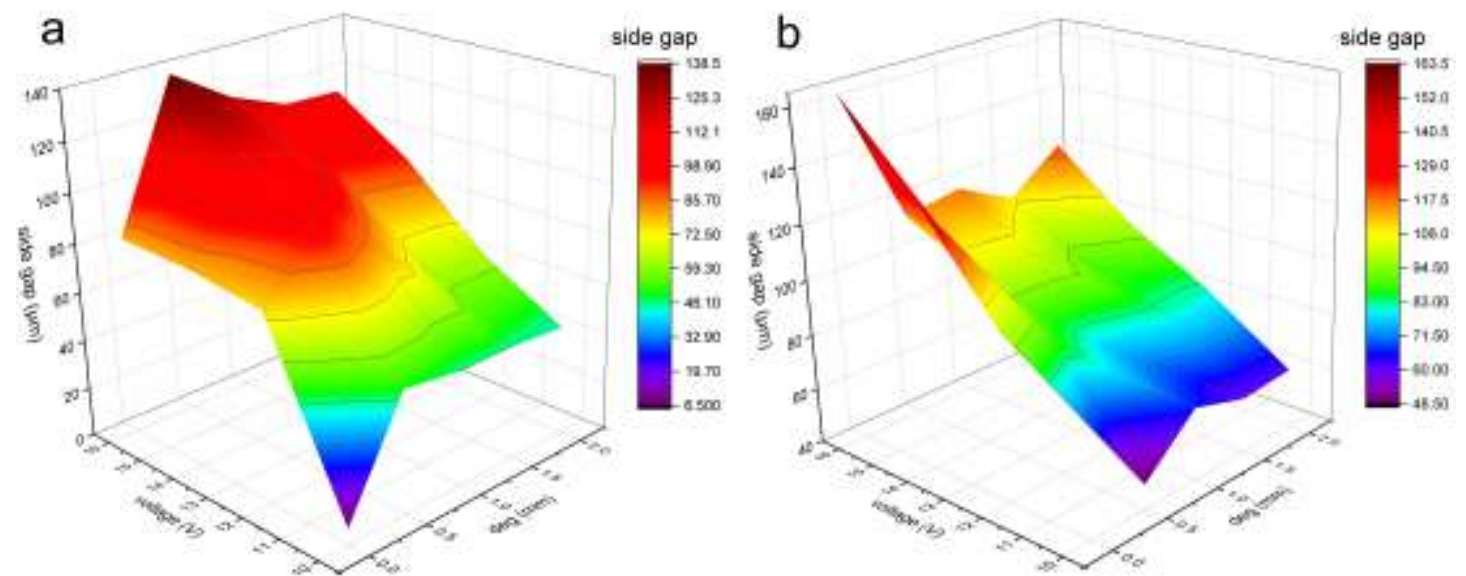

Fig. 13. Variation of the machining side gap with voltage and the retracted length deg in (a) the STEM process, and (b) the Laser-STEM process.

On the contrary, results have demonstrated that the machining side gap of Laser-STEM decreased while the retracted length deg increasing from 0 to $2 \mathrm{~mm}$. The side gap reached the maximum value when deg $=0 \mathrm{~mm}$, then decreased with the deg rising to $0.5 \mathrm{~mm}$ and tended to be stable with the deg further increasing. Compared with the STEM process, the action of laser could promote the center material removal rate and reduce the requirements of 
the electrochemical process in the center of the machining area. Hence, the drilling process could proceed well even when deg $=0 \mathrm{~mm}$. Therefore, the machining side gap could be decreased with the larger retracted length and smaller voltage in the Laser-STEM process.

\subsection{Influences of retracted length on materials removal rate}

In the Laser-STEM process, the materials removal rate is proportional to the hybrid tubular electrode feeding speed. Obviously, with a larger feeding speed, the processed holes or cavities have a larger machining depth, and the volume of the removed materials became larger. The previous studies also reported that the machining precision of STEM could be enhanced with the higher feeding speed of the tubular electrode [26]. As shown in Fig. 14 , with the retracted length deg rising from $0 \mathrm{~mm}$ to $1.5 \mathrm{~mm}$, the maximum feeding speed has been increased from $1.1 \mathrm{~mm} / \mathrm{min}$ to $4.1 \mathrm{~mm} / \mathrm{min}$ with a laser power of $6 \mathrm{~W}$, an increase of $373 \%$ of the feeding speed had been achieved. Also, with the increase of retracted length deg, the side gap of machined holes decreased from $46.5 \mu \mathrm{m}$ to $26.9 \mu \mathrm{m}$ with a laser power of $6 \mathrm{~W}$. Thus, experimental results proved that the retracted hybrid tubular electrode could increase both the machining efficiency and accuracy. Fig. 14 also indicated that under the same retracted length deg and voltage, the side gap and the maximum feed speed with a laser power of $10 \mathrm{~W}$ was smaller than that of $6 \mathrm{~W}$, due to the decrease of the laser coupling efficiency. Compared with the maximum feeding rate of about 2 $\mathrm{mm} / \mathrm{min}$ in the STEM process [27], thus, it has been improved by $105 \%$ by introducing laser to STEM with the proposed retracted hybrid tubular electrode.

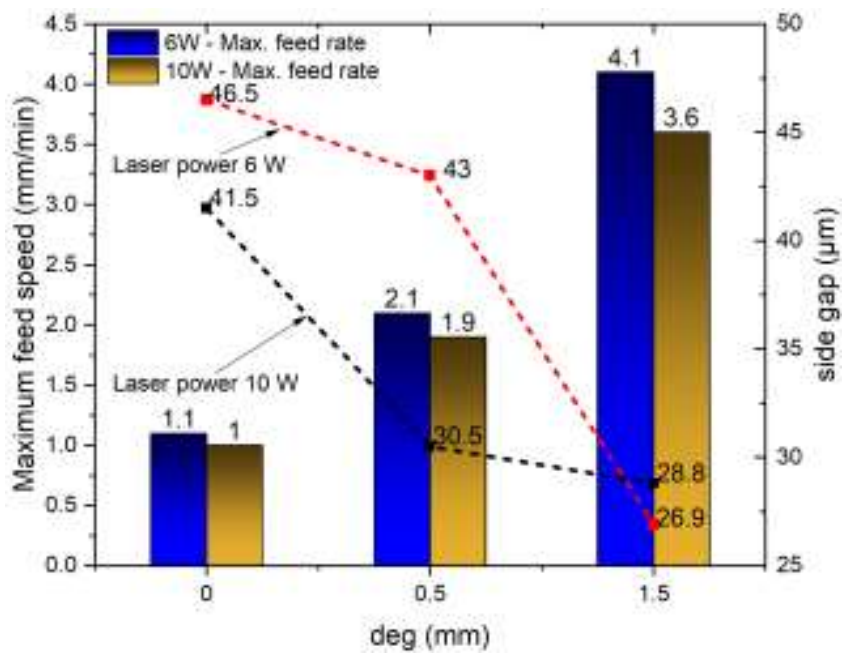

Fig. 14. The maximum feeding speed of the hybrid tubular electrode and the machining side gap of the cavities processed by the Laser-STEM process.

Concludingly, the utilization of the retracted hybrid tubular electrode could enhance both the machining efficiency and precision of the Laser-STEM process. As shown in Fig. 15, the small holes with a diameter of 1.4 $\mathrm{mm}$ and an aspect ratio of 15 have been processed by the Laser-STEM process with a retracted hybrid tubular electrode. A laser power of $6 \mathrm{~W}$, a voltage of $14 \mathrm{~V}$, a feeding rate of $3 \mathrm{~mm} / \mathrm{min}$, and a hybrid tubular electrode with a retracted length deg of $1.5 \mathrm{~mm}$ were utilized. This study could further improve the machining efficiency and precision of STEM, thus boosting its application in various industries. 


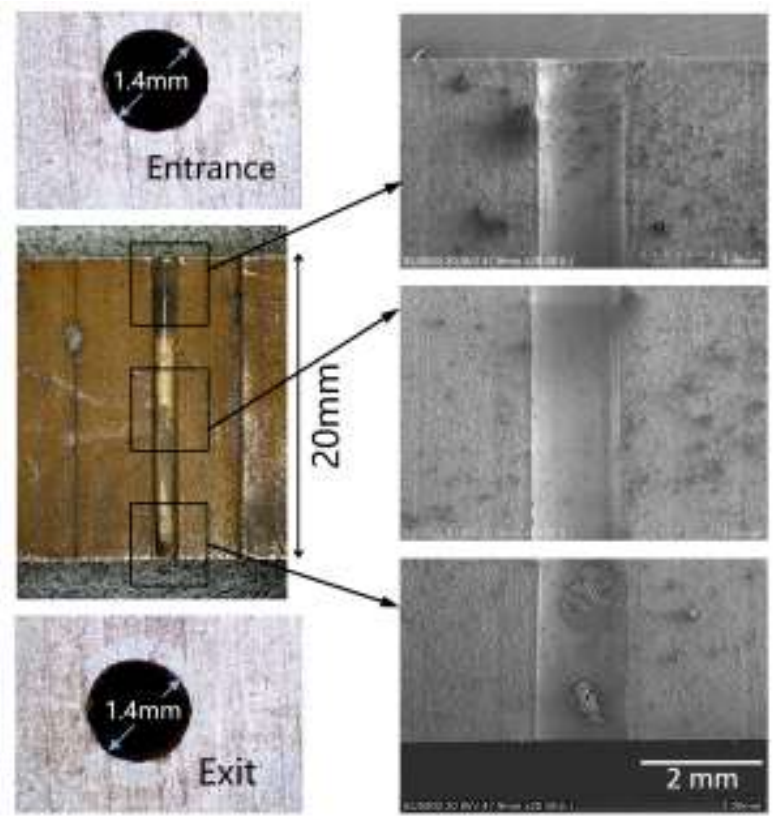

Fig. 15. The small hole of high aspect ratio processed by the Laser-STEM process utilizing a retracted hybrid tubular electrode.

\section{Conclusions}

A retracted hybrid tubular electrode has been introduced to the hybrid Laser-STEM process to improve both the machining efficiency and precision. Simulation and experiments were conducted to study and verify the effects of the retracted length of the tubular electrode. The conclusions could be summarized as follows:

(1) Simulation results showed that a retracted length of $1-1.5 \mathrm{~mm}$ of the inner low-refractive layer could improve the electric current distribution homogeneity in the machining area, which was beneficial to remove the W-shaped central residual in the machining area during Laser-STEM. The difference between the maximum and minimum electric current density in the machining zone decreased by $38 \%$ by using the hybrid tubular electrode with a retracted length of $2.0 \mathrm{~mm}$.

(2) With a proper retracted length, the laser coupling efficiency exceeded $74.5 \%$. Hence, the retracted hybrid tubular electrode could act as both the tool electrode and optical waveguide in the Laser-STEM process.

(3) Experimental results proved that a larger retracted length and high laser power were preferred to eliminate the residual volume, and thus improve the machining stability of Laser-STEM.

(4) Both the machining efficiency and precision of Laser-STEM could be enhanced by utilizing the retracted hybrid tubular electrode. With the retracted length deg rising from $0 \mathrm{~mm}$ to $1.5 \mathrm{~mm}$, the maximum feeding speed increased by $373 \%$, and the machining precision was improved by $42.2 \%$. The maximum feeding rate of 4.1 $\mathrm{mm} / \mathrm{min}$ has been achieved using the retracted hybrid tubular electrode in the Laser-STEM process, which has been improved by $105 \%$ compared with the available maximum feeding rate of the tubular electrode in the STEM process.

(5) The small holes with a diameter of $1.4 \mathrm{~mm}$ and an aspect ratio of 15 have been processed by Laser-STEM with the retracted hybrid tubular electrode. 


\section{Declarations}

\section{Funding}

This research was supported by the National Natural Science Foundation of China (51905525), the Natural Science Foundation of Zhejiang (LQ19E050003), the key research and development program of Zhejiang (2020C01036), and the Natural Science Foundation of Ningbo (2019A610152).

\section{Conflicts of interest/Competing interests}

We declare that we do not have any commercial or associative interest that represents a conflict of interest in connection with the work submitted.

\section{Availability of data and material}

The datasets used or analyzed during the current study are available from the corresponding author on reasonable request.

\section{Code availability}

Not applicable.

\section{Authors' contributions}

Yufeng Wang contributed to the conception of the study, and guided experiments and conclusions;

Yong Yang performed the experiment, analyzed the data, and completed the manuscript;

Yujie Gui, Fuhui Shao, and Yulei Li assisted to experiment;

Wenwu Zhang funded the study.

Ethics approval

Not applicable.

\section{Consent to participate}

This study was involved no ethical issues.

\section{Consent for publication}

This study was involved no ethical issues.

\section{References}

[1] Z.Y. Li, X.T. Wei, J.J. Sun, C.W. Zang, C.H. Fu, Y.B. Guo (2015) Process capability and effect size of vacuum extraction shaped tube electrolytic drilling of Inconel alloy for high-performance cooling hole, The International Journal of Advanced Manufacturing Technology 85:2557-2566

[2] J. Kozak, K. P. Rajurkar, Y. Makkar (2004) Study of Pulse Electrochemical Micromachining, Journal of Manufacturing Processes 1:7-14

[3] K.P. Rajurkar, D. Zhu, J.A. Mcgeough, J. Kozak, A.D. Silva (1999) New Developments in Electro-Chemical Machining, CIRP Annals - Manufacturing Technology 48:567-579

[4] D. S. Bilgi, V. K. Jain, R. Shekhar, S. Mehrotra (2004) Electrochemical deep hole drilling in super alloy for turbine application, Journal of Materials Processing Technology 149:445-452

[5] L. Yong and H. Ruiqin (2013) Micro electrochemical machining for tapered holes of fuel jet nozzles, 


\section{Procedia CIRP 6:395-400}

[6] M. Datta and L. T. Romankiw (1989) Application of chemical and electrochemical micromachining in the electronics industry, Journal of The Electrochemical Society 136:285C-292C

[7] B.J. Park, B.H. Kim, C.N. Chu (2006) The effects of tool electrode size on characteristics of micro electrochemical machining, CIRP Annals - Manufacturing Technology 55:197-200

[8] C. Jackson, R. D. Olson (1969) Shaped tube electrolytic machining (STEM drilling), SME Technique Paper 69-109

[9] M. Sen, H. S. Shan (2005) A Review of Electrochemical Macro- to Micro-hole Drilling Processes, International Journal of Machine Tools \& Manufacture 45:137-152

[10] J. A. McGeough (1974) Principles of Electrochemical Machining, Chapman and Hall

[11] K. P. Rajurkar, B. Wei, J. Kozak, J.A. Mcgeough (1995) Modelling and Monitoring Interelectrode Gap in Pulse Electrochemical Machining. CIRP Annals - Manufacturing Technology 44:177-180

[12] J. Kozak, K.P. Rajurkar, Y. Makkar (2004) Selected Problems of Micro-electrochemical Machining, Journal of Materials Processing Technology 149:426-431

[13] S. Skoczypiec (2011) Research on ultrasonically assisted electrochemical machining process, The International Journal of Advanced Manufacturing Technology 52:565-574

[14] X.D. Wang, N.S. Qu, X.L. Fang, H. Li (2016) Electrochemical drilling with constant electrolyte flow, Journal of Materials Processing Technology 238:1-7

[15] M. Deepak, S.S. Joshi, S.K. Mitra (2008) Modeling of Electrochemical Micromachining: Comparison to Experiments, Journal of Micro/ Nanolithography, MEMS, and MOEMS 7:033015

[16] Y. Wang, F. Yang, G. Zhang, W Zhang (2019) Fabrication of deep and small holes by synchronized laser and shaped tube electrochemical machining (Laser-STEM) hybrid process, The International Journal of Advanced Manufacturing Technology 105:2721-2731

[17] L. Tang, Y.F. Guo (2013) Experimental Study of Special Purpose Stainless Steel on Electrochemical Machining of Electrolyte Composition, Materials and Manufacturing Processes 28:457-462

[18] M.S. Hewidy, S.J. Ebeid, K.P. Rajurkar (2001) Electrochemical machining under orbital motion conditions, Journal of Materials Processing Technology 109:339-346

[19] Y. Zhang, N.S. Qu, X.L. Fang, X.D. Wang (2019) Eliminating spikes by optimizing machining parameters in electrochemical drilling. Journal of Manufacturing Processes 37:488-495

[20] H. Zhang, J. Xu, J. Wang (2009) Investigation of a novel hybrid process of laser drilling assisted with jet electrochemical machining, Optics \& Lasers in Engineering 47:1242-1249

[21] P.T. Pajak, A.K.M. Desilva, D.K. Harrison, J.A. Mcgeough (2006) Precision and efficiency of laser assisted jet electrochemical machining, Precision Engineering 30:288-298

[22] Y.F. Wang, W.W. Zhang (2021) Theoretical and experimental study on hybrid laser and shaped tube electrochemical machining (Laser-STEM) process, The International Journal of Advanced Manufacturing Technology 112:1601-1615

[23] A.K.M. Desilva, P.T. Pajak, D.K. Harrison, J.A. Mcgeough (2004) Modelling and experimental investigation of laser assisted jet electrochemical machining, CIRP Annals 53:179-82

[24] K.K. Saxena, J. Qian, D. Reynaerts (2020) A tool-based hybrid laser-electrochemical micromachining process: Experimental investigations and synergistic effects, International Journal of Machine Tools and Manufacture 155:103569

[25] D. Zhu, H.Y. Xu (2002) Improvement of electrochemical machining accuracy by using dual pole tool, Journal of Materials Processing Technology 129:15-18

[26] X.L. Fang, N.S. Qu, Y. Zhang, Z. Xu, Z. Di (2014) Effects of pulsating electrolyte flow in electrochemical machining, Journal of Materials Processing Technology 214:36-43 
[27] X.D. Wang, N.S. Qu, X.L. Fang, H. Li (2016) Electrochemical drilling with constant electrolyte flow, Journal of Materials Processing Technology 238:1-7 
Figures
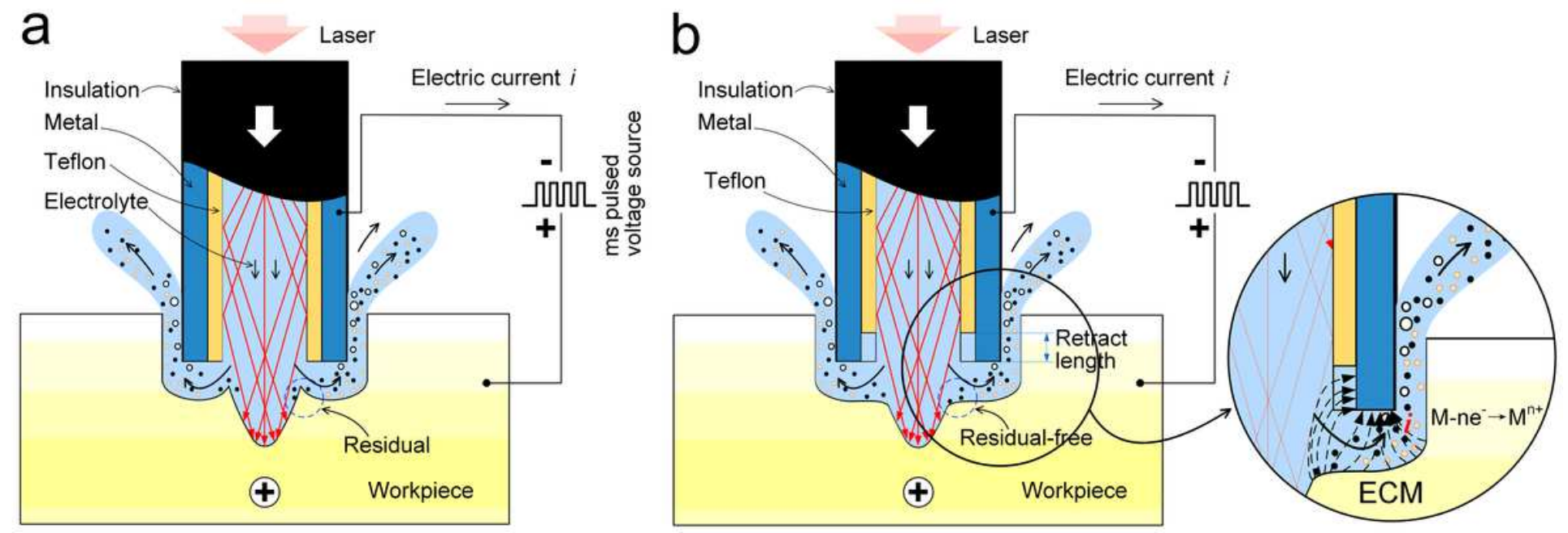

Figure 1

Schematic diagram of the hybrid laser and shaped tube electrochemical machining (Laser-STEM) process using (a) a flat-ended hybrid tubular electrode, and (b) a retracted hybrid tubular electrode. 


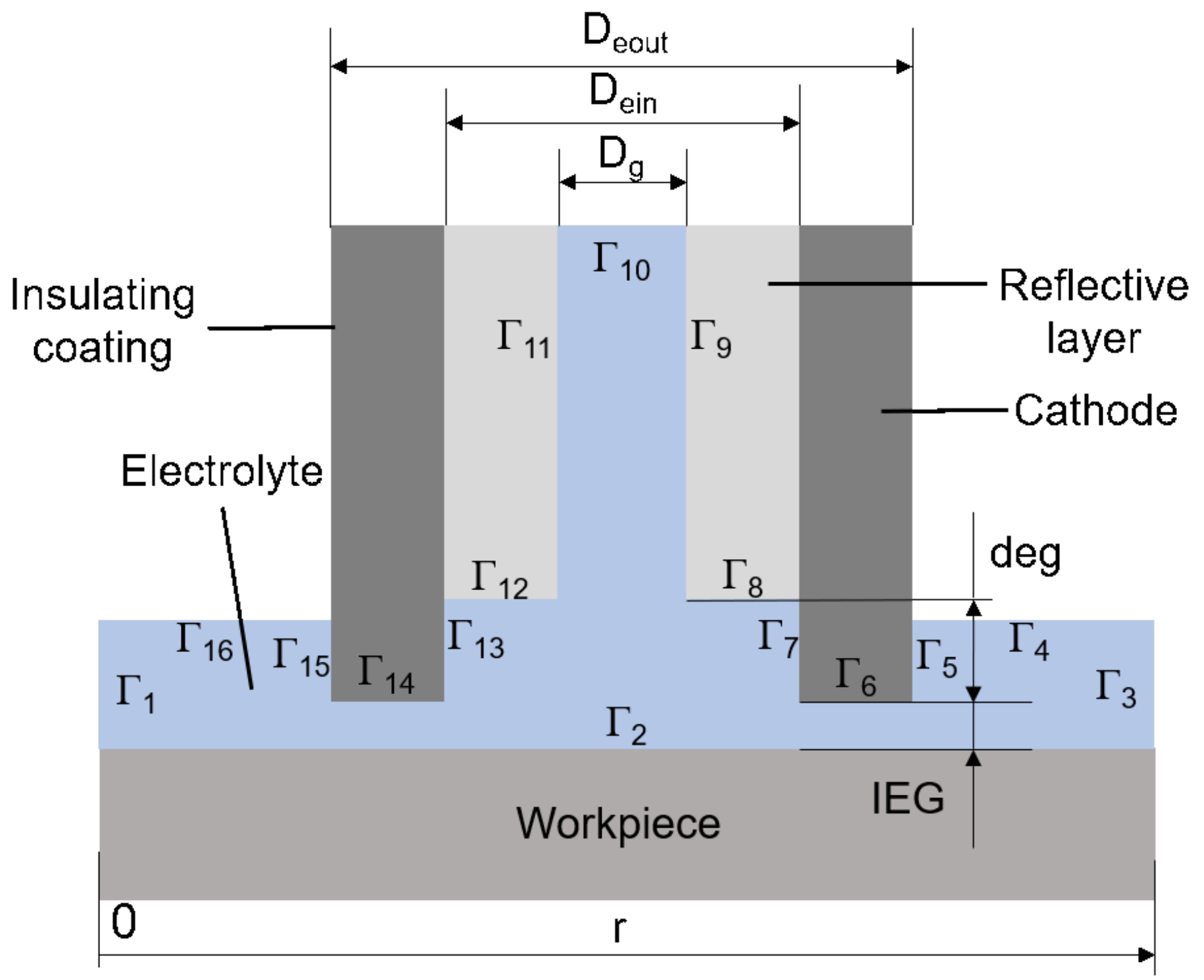

Figure 2

The electric potential domain of the hybrid laser and shaped tube electrochemical machining process. 


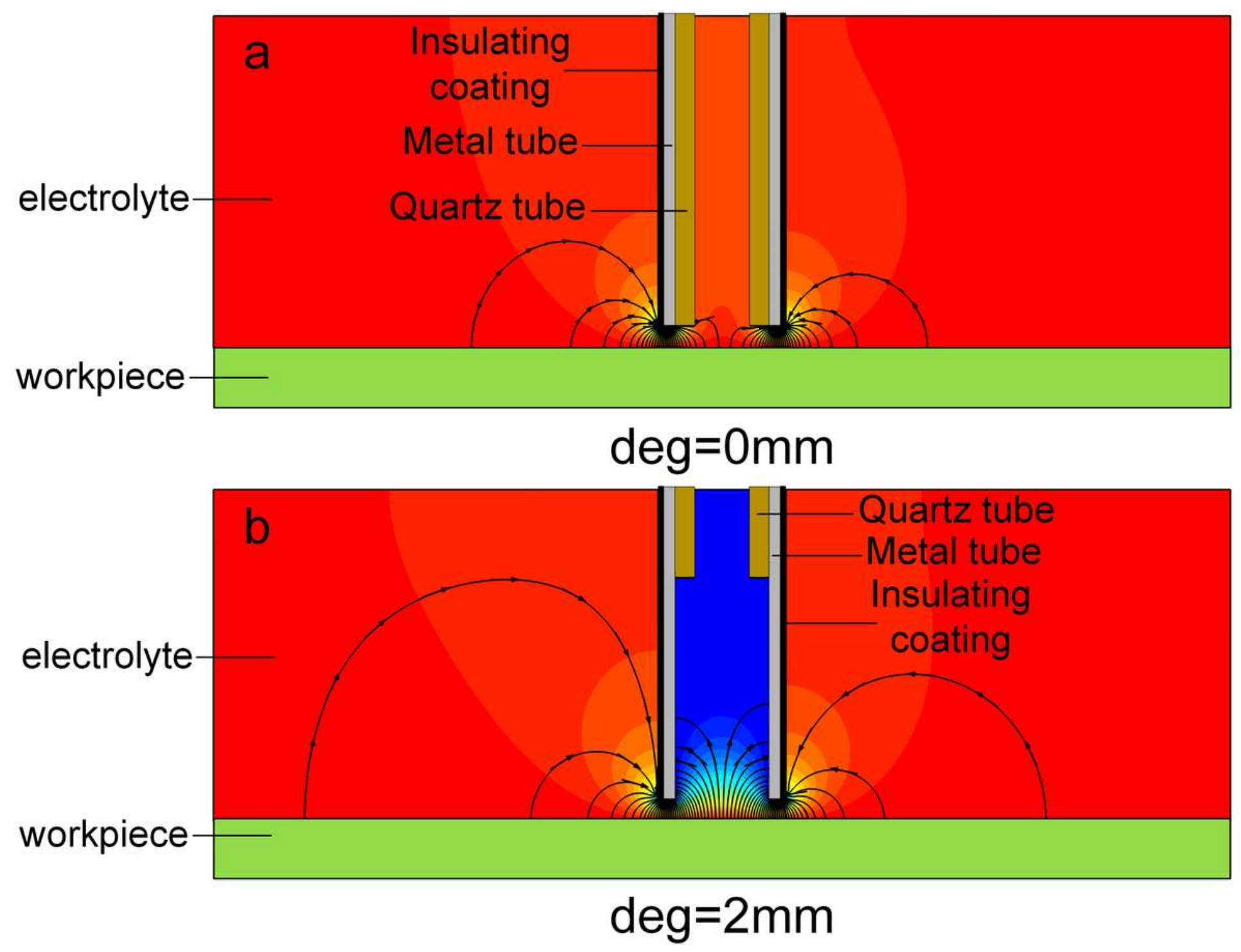

Figure 3

The electric current line distributions in machining zone with $10 \mathrm{~V}$ voltage and $0.2 \mathrm{~mm}$ IEG, with the retracted length of (a) deg=0 $\mathrm{mm}$, (b) deg=2 $\mathrm{mm}$. 
a

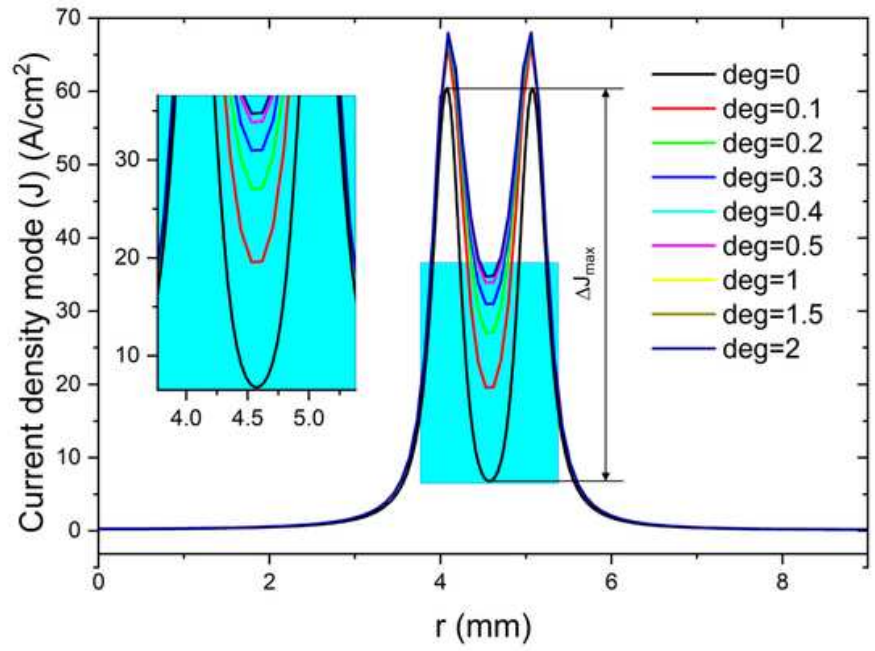

b

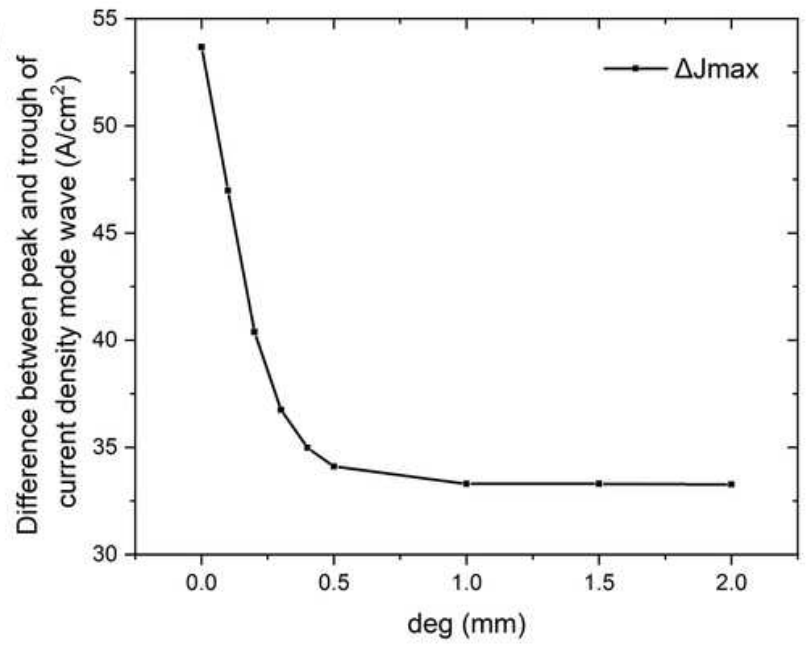

Figure 4

(a) The distribution of electric current density at the machining area in the Laser-STEM process, (b) Variation of the difference between the maximum and minimum electric current density $\Delta \mathrm{Jmax}$ with the retracted length.

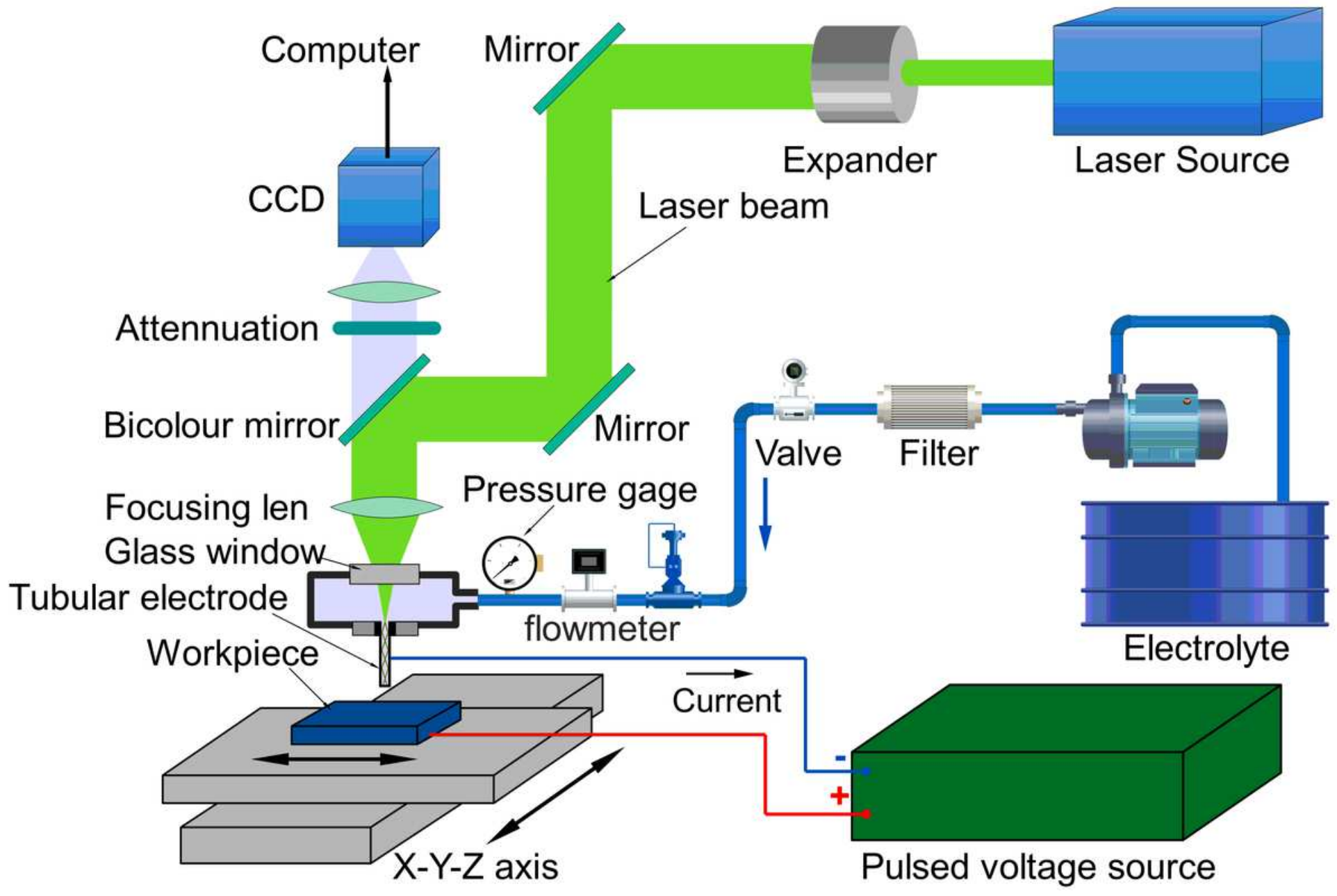

Figure 5 
Schematic diagram of the developed experimental setup for the hybrid laser-STEM process.

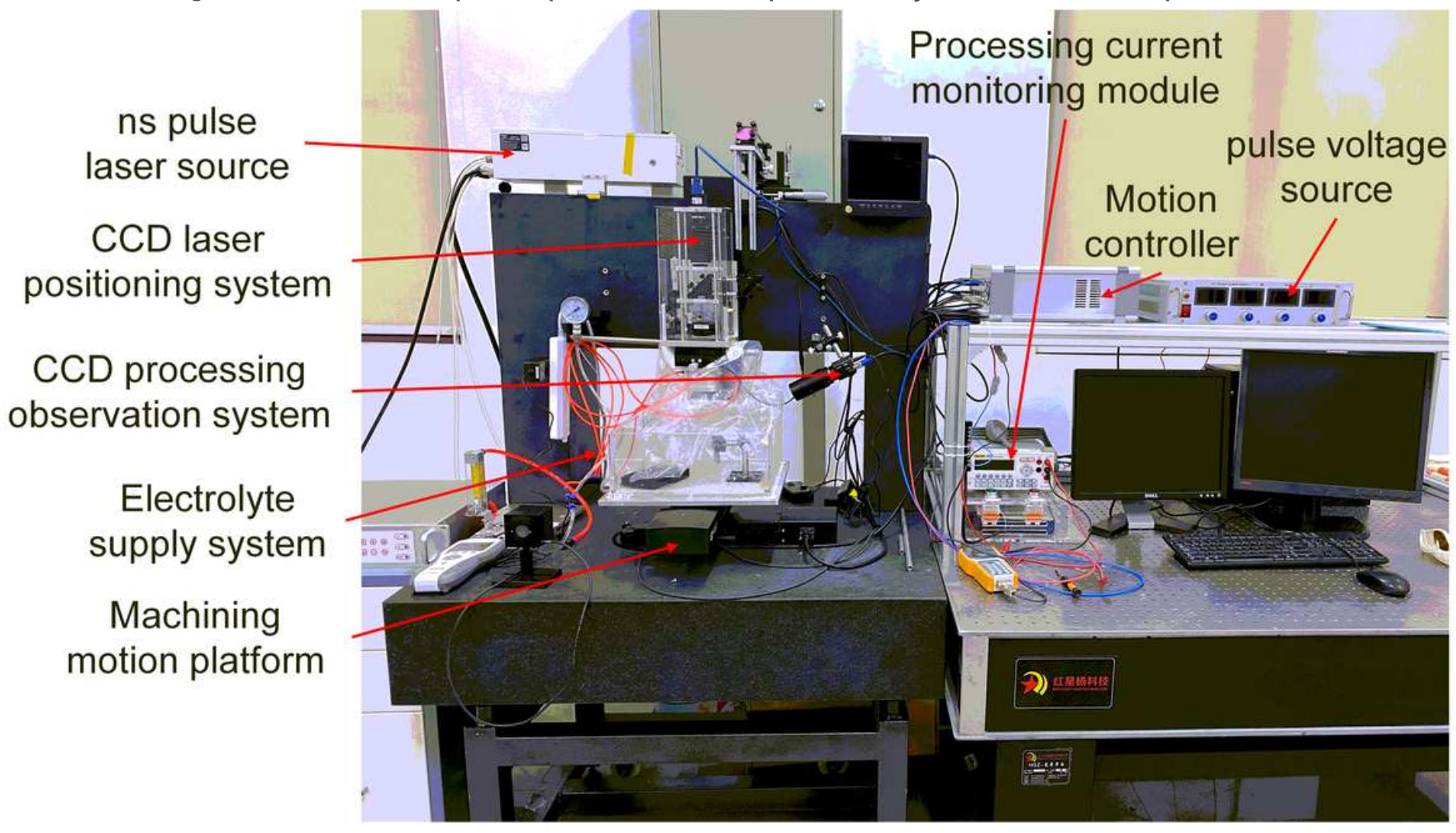

Figure 6

Photograph of the developed experimental setup for the hybrid laser-STEM process.
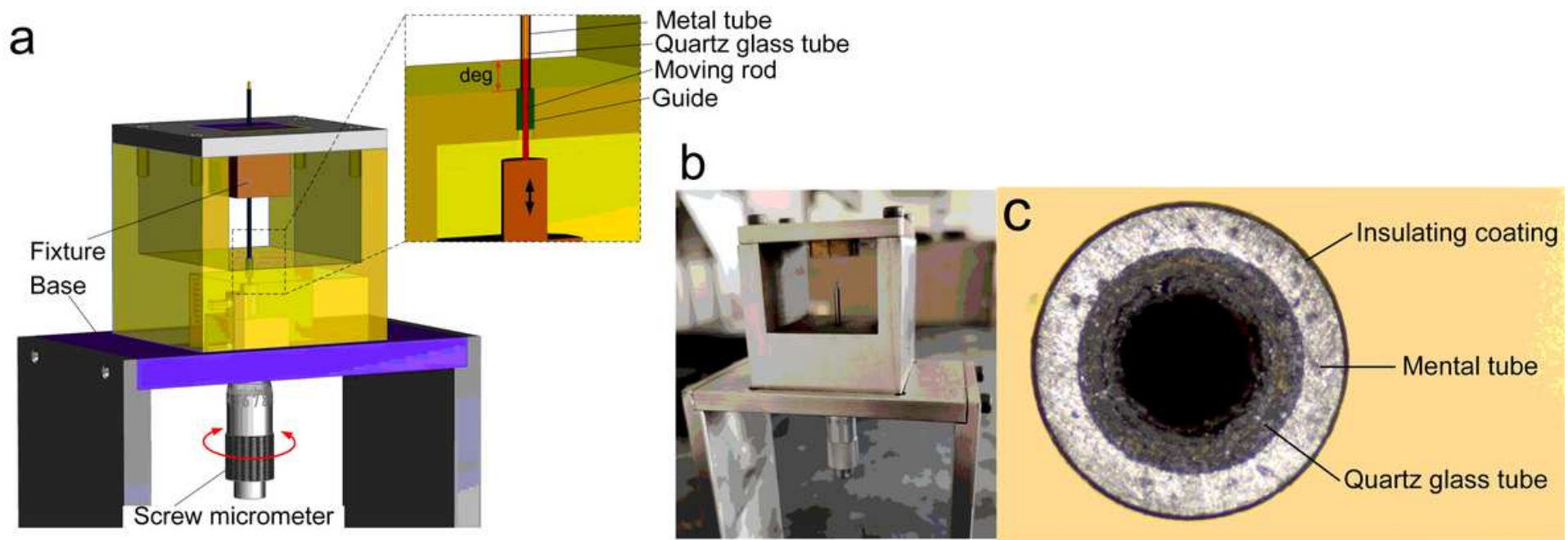

Figure 7

(a) Three-dimensional model of the developed instrument for preparing the hybrid tubular electrode with the controlled retracted length, (b) the photograph of this developed instrument, (c) the cross-section of the developed hybrid tubular electrode with the controlled retracted length. 


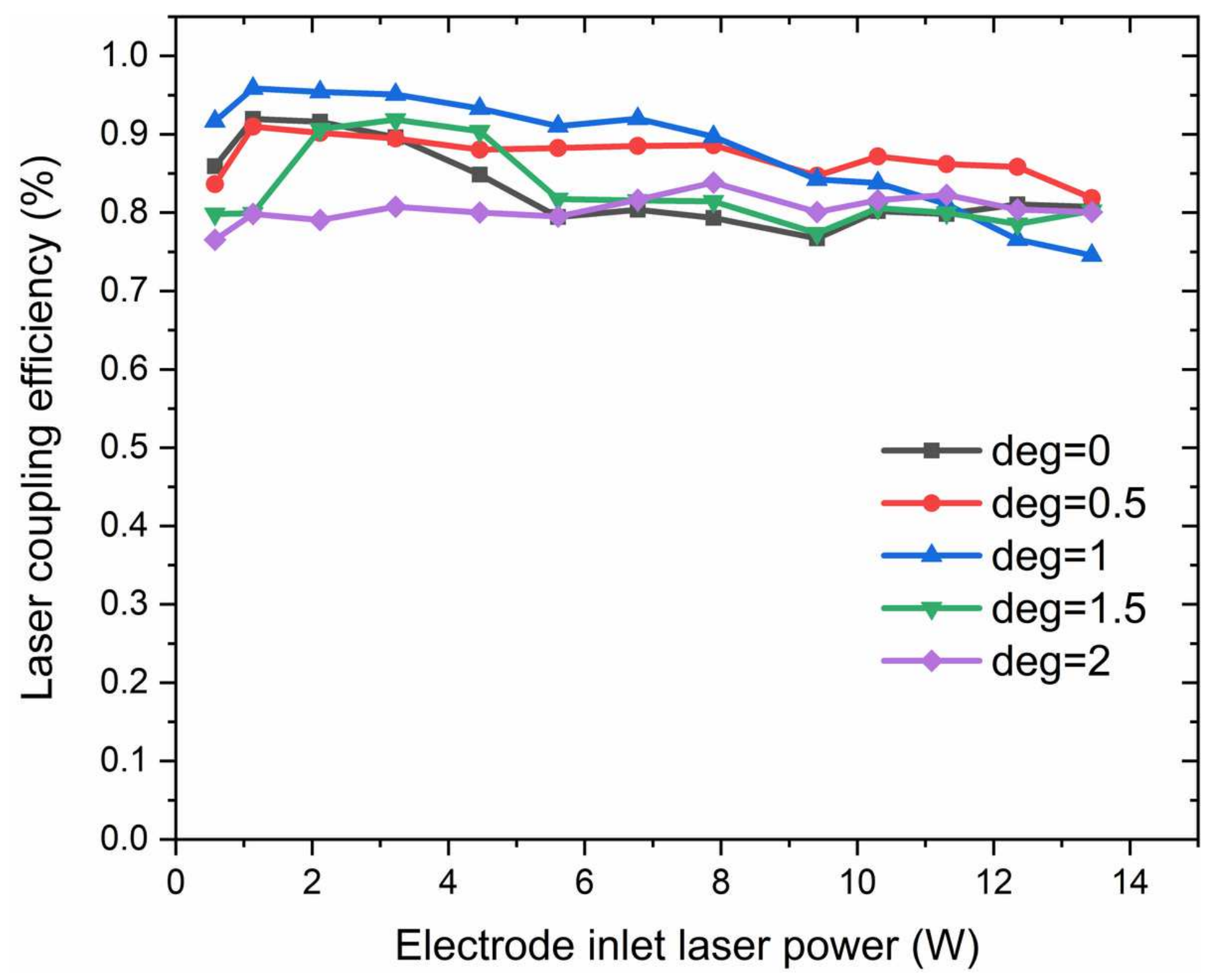

Figure 8

Variation of the laser coupling efficiency with the electrode inlet laser power and the retracted length of deg ranging from 0 to $2 \mathrm{~mm}$. 
$700.0 \mathrm{um}$
500.0
500.0
400.0
300.0
200.0
100.0
0.0

1000.

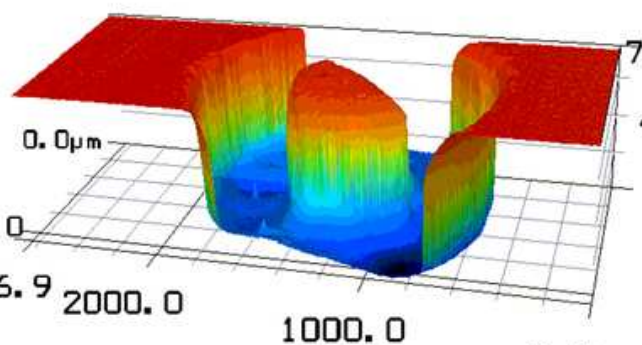

0. $0 \mu \mathrm{m}$
0
$2636 .{ }^{9} 2000.0$
763. $\left.3 \mu \mathrm{m} \quad\right|_{0.0} ^{200.0}$ 400. 0

0. 0
$1000.0 \mathrm{\mu m}$
800.0
500.0
400.0
200.0
0.0

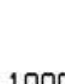

1000. 2636. 9 2000. b

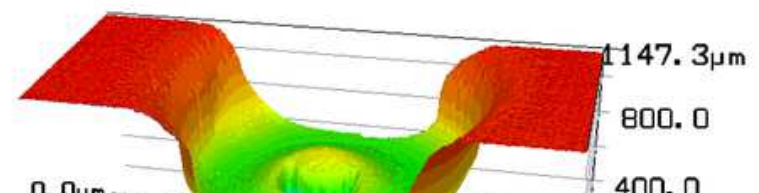

0.0

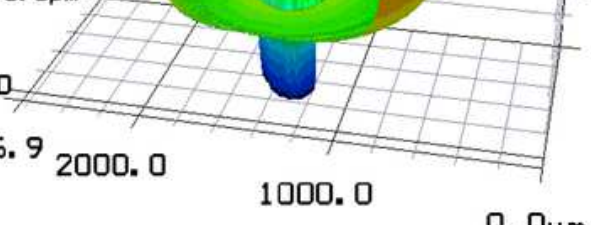

Q. $0 \mu \mathrm{m}$
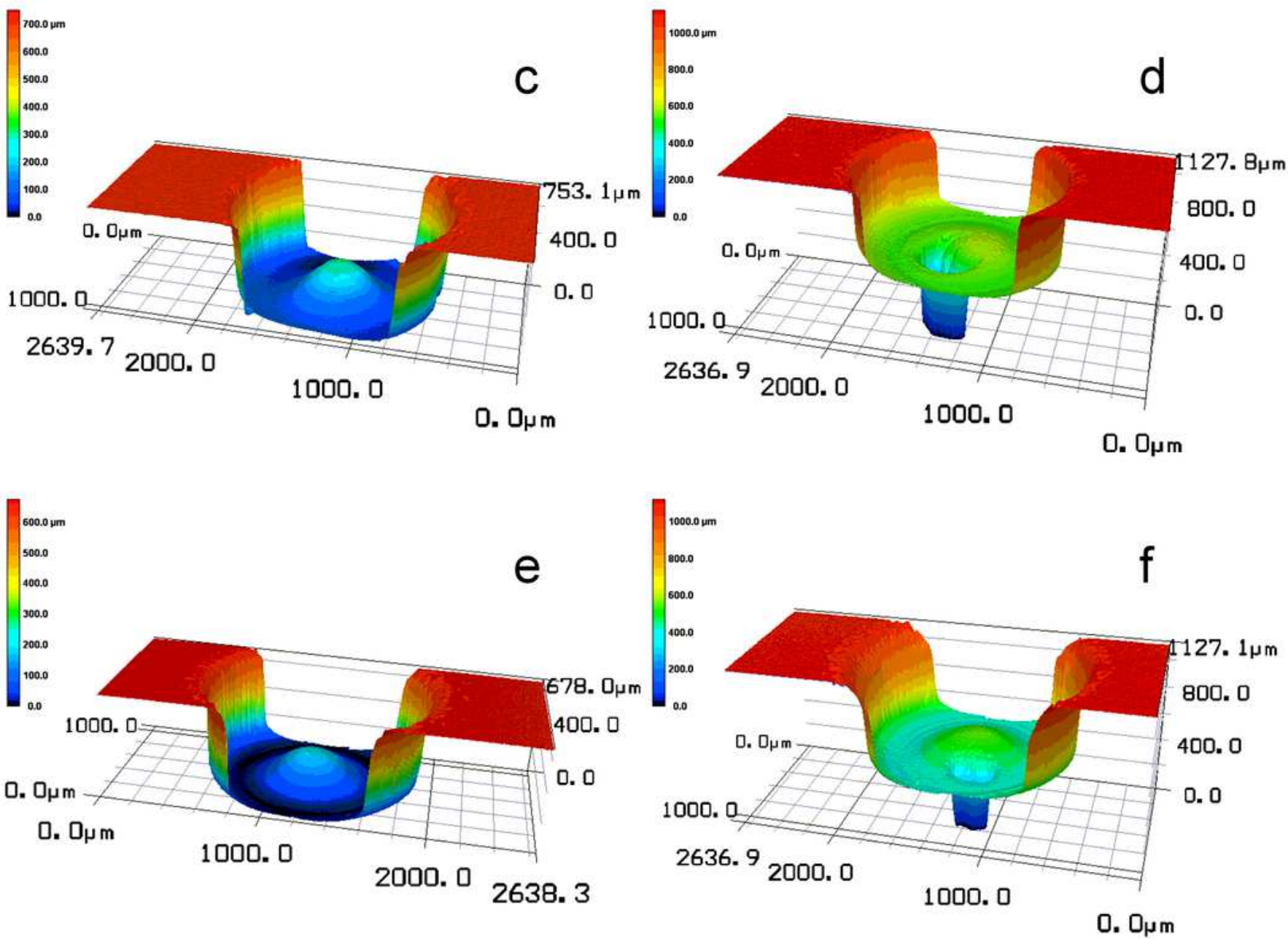

Figure 9

Comparison of the 3-D morphology of the processed cavities with different machining parameter, (a), (c), (e) the cavities processed by STEM without laser, (b), (d), (f) the cavities processed by the Laser-STEM process, (a), (b) deg $=0 \mathrm{~mm}$ and $\mathrm{Uw}=14 \mathrm{~V},(\mathrm{c}),(\mathrm{d}) \mathrm{deg}=0.5 \mathrm{~mm}$ and $\mathrm{Uw}=14 \mathrm{~V},(\mathrm{e})$, (f) deg $=1.5 \mathrm{~mm}$ and $\mathrm{UW}=14 \mathrm{~V}$. 

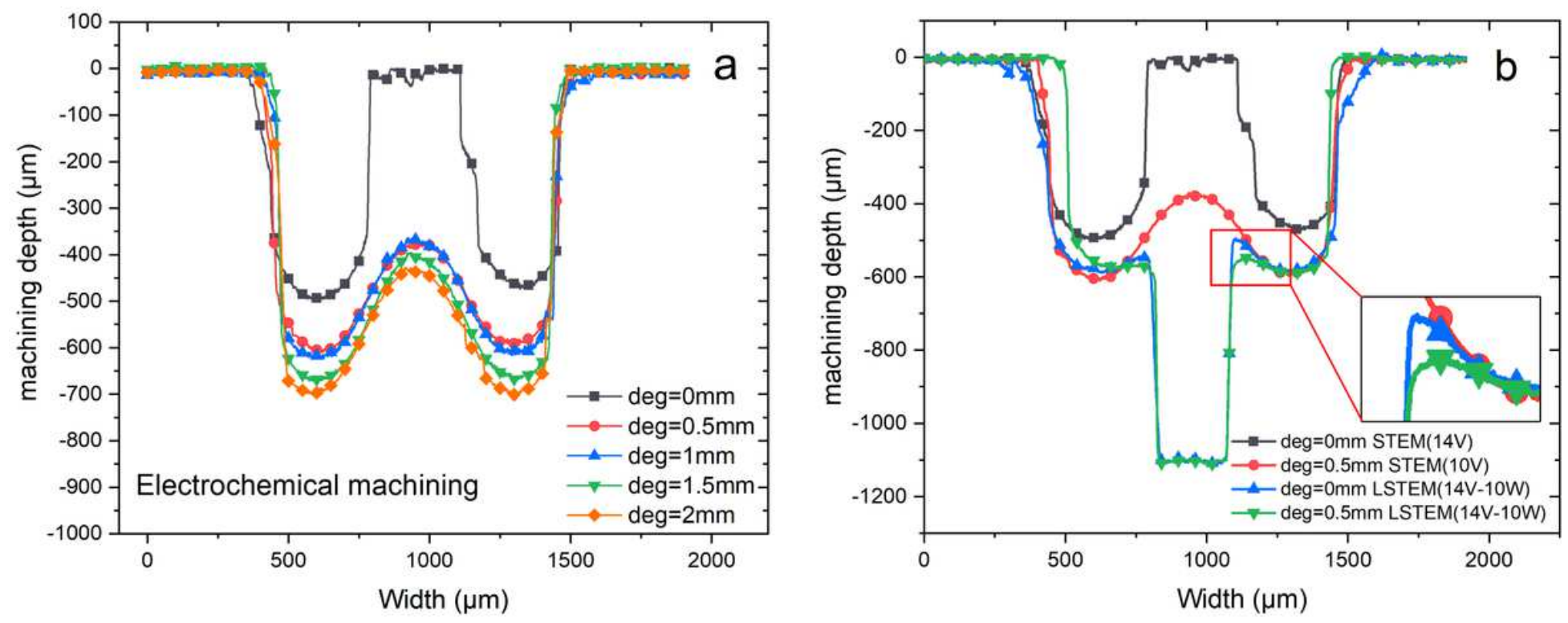

Figure 10

(a) The cross-sectional profiles of processed cavities by STEM without laser assistance, (b) Comparison of the cross-sectional profiles of the processed cavities by STEM without laser assistance and the LaserSTEM process. 


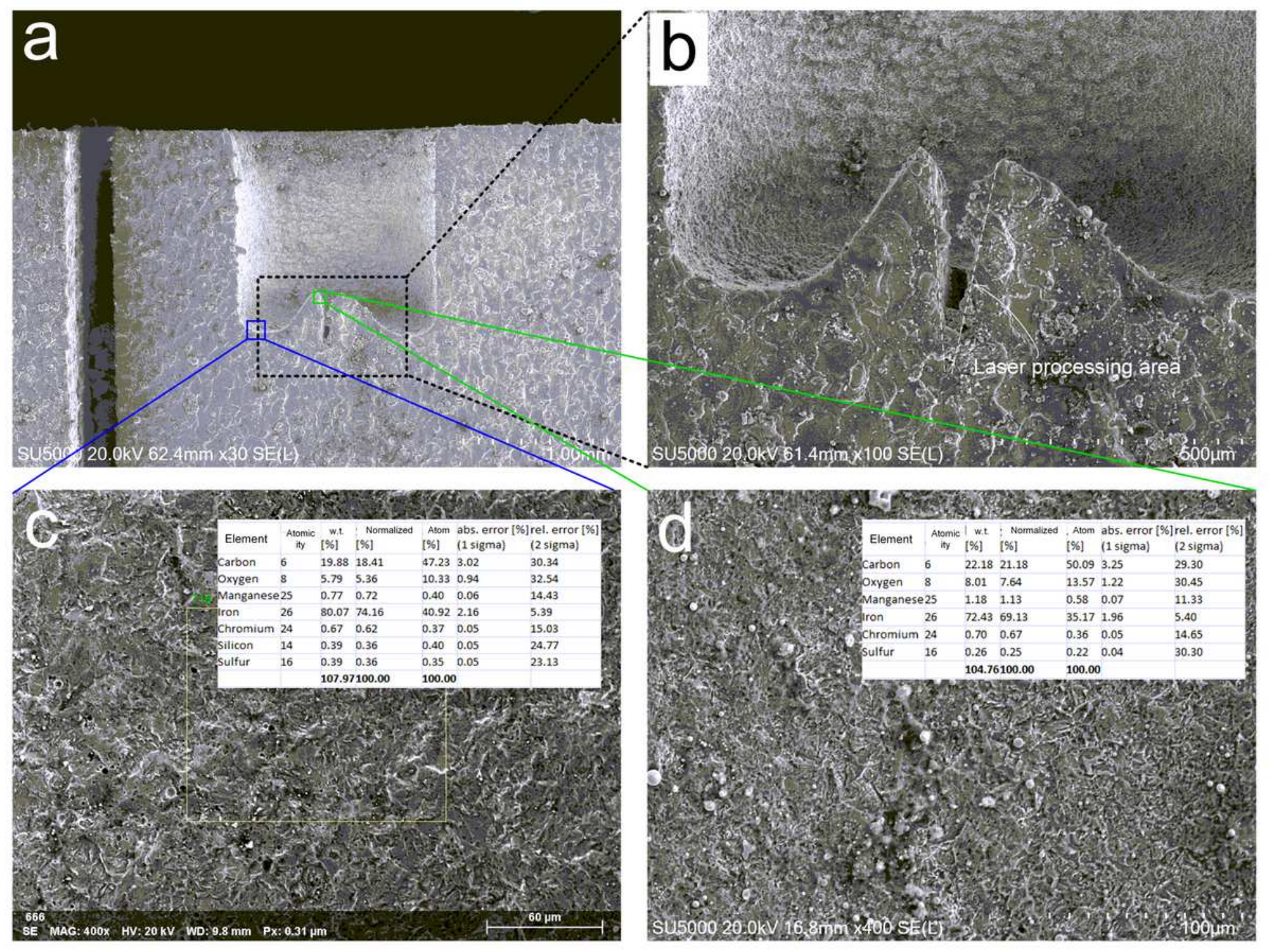

\section{Figure 11}

(a) SEM images of the cavities processed by the Laser-STEM process, (b) the enlarged SEM image of the central machining area, (c) SEM image and EDS analysis of laser assisted ECM area, (d) SEM image and EDS analysis of the laser processing area.
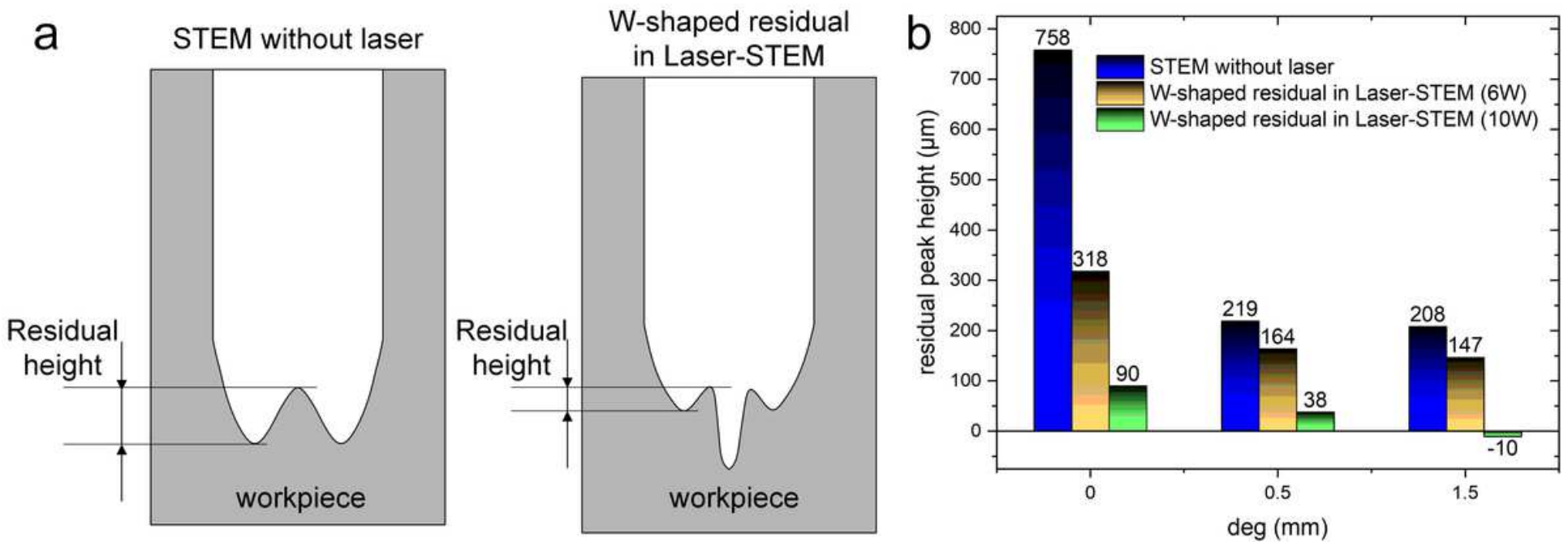
Figure 12

(a) Schematic illustration of the residual peak height of the machined cavities processed by the STEM and the Laser-STEM processes, (b) variation of the residual peak height with the retracted length of $0,0.5$ $\mathrm{mm}$, and $1.5 \mathrm{~mm}$ in the STEM and the Laser-STEM processes.
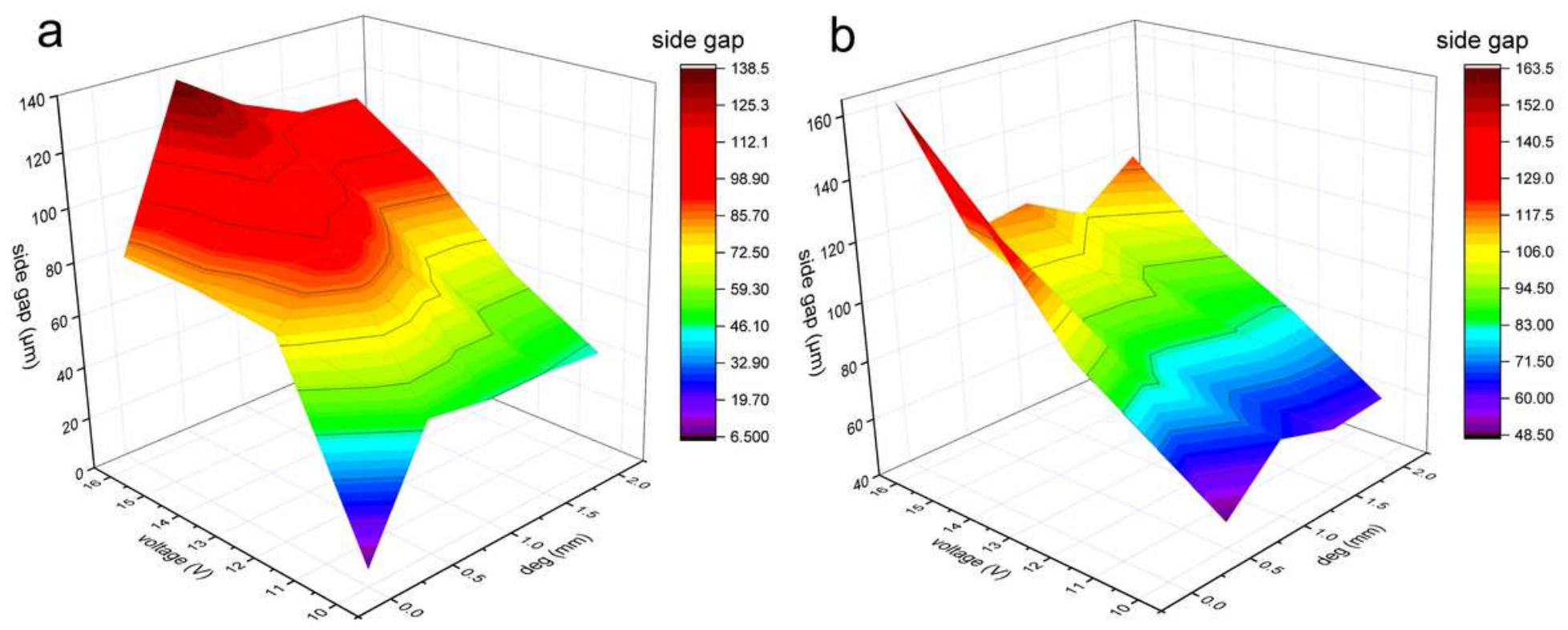

Figure 13

Variation of the machining side gap with voltage and the retracted length deg in (a) the STEM process, and (b) the Laser-STEM process. 


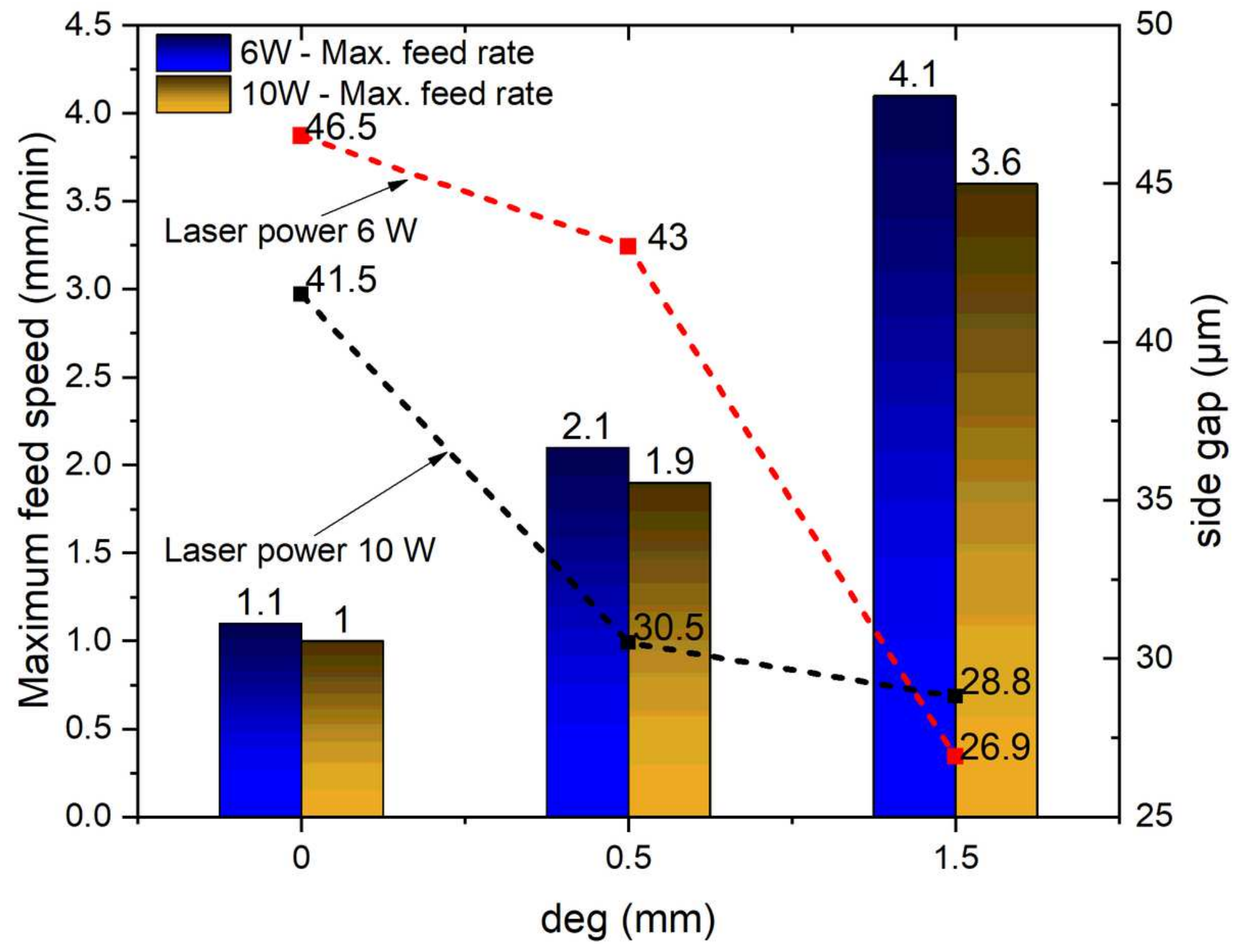

Figure 14

The maximum feeding speed of the hybrid tubular electrode and the machining side gap of the cavities processed by the Laser-STEM process. 


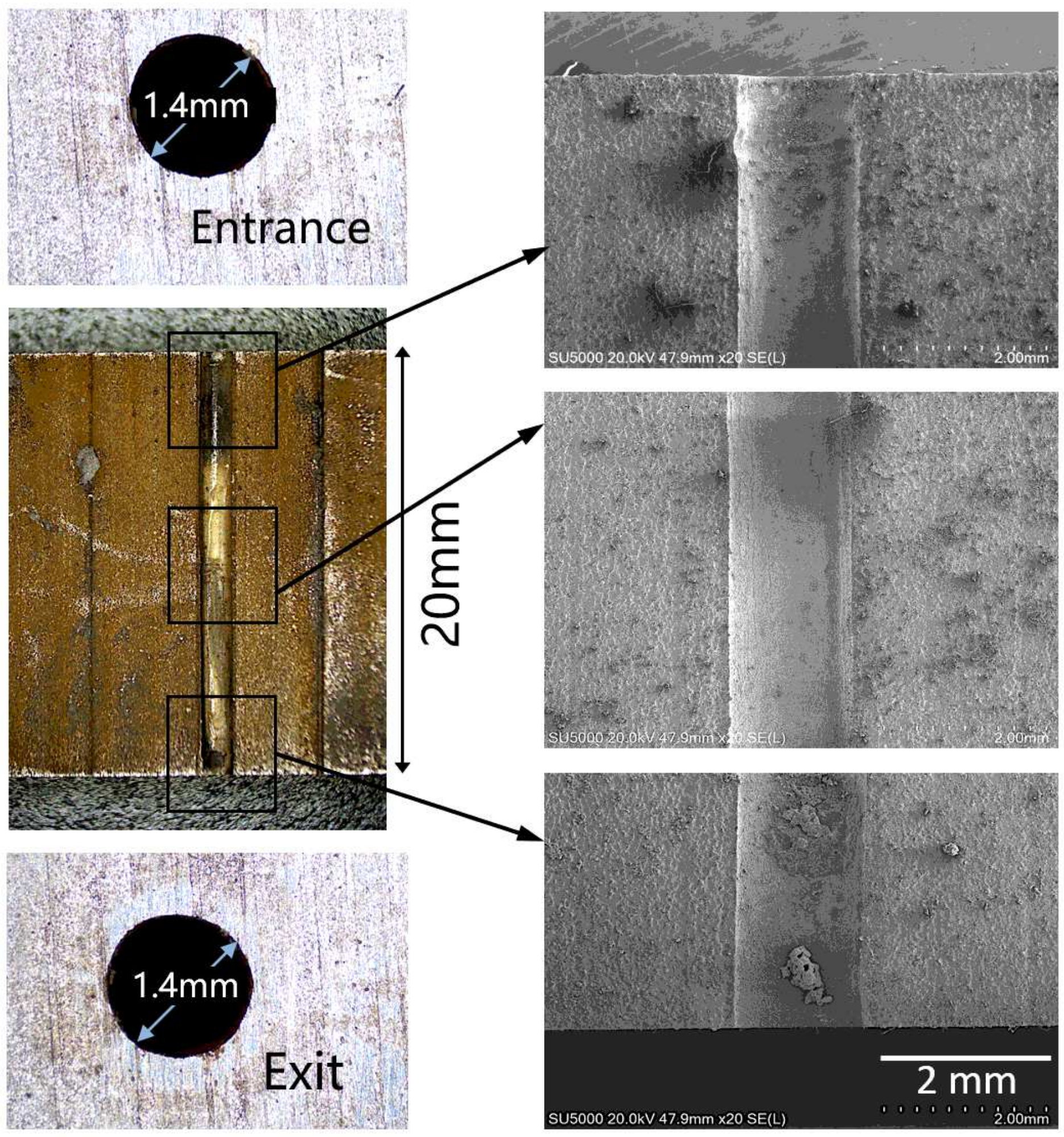

Figure 15

The small hole of high aspect ratio processed by the Laser-STEM process utilizing a retracted hybrid tubular electrode. 